NBER WORKING PAPER SERIES

\title{
IS DRUG COVERAGE A FREE LUNCH? CROSS-PRICE ELASTICITIES AND THE DESIGN OF PRESCRIPTION DRUG BENEFITS
}

\author{
Martin Gaynor \\ Jian Li \\ William B. Vogt \\ Working Paper 12758 \\ http://www.nber.org/papers/w12758 \\ NATIONAL BUREAU OF ECONOMIC RESEARCH \\ 1050 Massachusetts Avenue \\ Cambridge, MA 02138 \\ December 2006
}

We are greatly indebted to the NBER for the use of the Medstat data, and we express our sincere thanks to Ms. Jean Roth for her kind assistance. We are grateful for comments from Roger Feldman, Jonathan Gruber, Sean Nicholson, Mike Chernew, Avi Dor, Tomas Philipson and participants at the 2005 Annual Health Economics Conference, the Spring 2005 NBER Health Care Program Meeting, and the 2006 Annual Meeting of American Society of Health Economists in Madison. The usual caveat applies. The views expressed herein are those of the author(s) and do not necessarily reflect the views of the National Bureau of Economic Research.

(C) 2006 by Martin Gaynor, Jian Li, and William B. Vogt. All rights reserved. Short sections of text, not to exceed two paragraphs, may be quoted without explicit permission provided that full credit, including (C) notice, is given to the source. 
Is Drug Coverage a Free Lunch? Cross-Price Elasticities and the Design of Prescription Drug Benefits

Martin Gaynor, Jian Li, and William B. Vogt

NBER Working Paper No. 12758

December 2006

JEL No. D12,I10,M50

\begin{abstract}
Recently, many U.S. employers have adopted less generous prescription drug benefits. In addition, the U.S. began to offer prescription drug insurance to approximately 42 million Medicare beneficiaries in 2006. We use data on individual health insurance claims and benefit data from 1997-2003 to study the effects of changing consumers' co-payments for prescription drugs on the quantity demanded and expenditure on prescription drugs, inpatient care and outpatient care. We allow for effects both in the year of the co-payment change and in the year following the change. Our results show that increases in prescription drug prices reduce both the use of and spending on prescription drugs. However, consumers substitute the use of outpatient care and inpatient care for prescription drug use, and about $35 \%$ of the expenditure reductions on prescription drugs are offset by the increases in other spending.

Martin Gaynor

H. John Heinz III School of

Public Policy and Management

Carnegie Mellon University

4800 Forbes Avenue, Room 241

Pittsburgh, PA 15213-3890

and NBER

mgaynor@andrew.cmu.edu

William B. Vogt

H. John Heinz III School of

Public Policy and Management

Carnegie Mellon University

4800 Forbes Ave, Room 2116D

Pittsburgh, PA 15213

and NBER

wilibear@andrew.cmu.edu
\end{abstract}

Jian Li

Carnegie Mellon University

Hamburg Hall 1113

5000 Forbes Avenue

Pittsburgh, PA 15213-3890

jianl@andrew.cmu.edu 


\section{Introduction}

In the past 15 years, national spending on prescription drugs has grown dramatically, far outpacing the growth rate of hospital spending and physician spending during the same period. ${ }^{1}$ In response to these rapid increases in drug spending, many health insurance plans have reduced the generosity of their prescription drug benefits. Consequently, patients have been paying substantially more out of their own pockets for prescription drugs in recent years. Ostensibly, benefit designers are seeking to reduce drug spending by increasing the price faced by consumers, the co-payment.

A number of studies have investigated the relationship between cost-sharing and spending on drugs (Joyce et al., 2001; Goldman et al., 2004; Huskamp et al., 2003; Soumerai et al., 1987, 1991; Harris et al., 1990; Johnson et al., 1997; Tamblyn et al., 2001; Motheral and Fairman, 2001). Almost all of these studies suggest that higher cost-sharing reduces pharmaceutical use. In addition, some studies have found that higher drug cost-sharing results in worsened health status (Johnson et al., 1997), and more adverse health events such as emergency room visits, nursing home admissions, or hospital admissions (Soumerai et al., 1991; Tamblyn et al., 2001; Balkrishnan et al., 2001). These findings suggest that the reduction in drug spending may come with unintended consequences. Achieving reduced drug use may come at the cost of worse health consequently leading to use of expensive care such as the emergency room or inpatient hospital care.

There is also a literature addressing substitution among different categories of medical care. Substitution between inpatient and outpatient care is studied by Davis and Russell (1972) and

\footnotetext{
${ }^{1}$ Spending on prescription drugs in 2004 was nearly five times the level in 1990. Spending on physician and hospital services were a little over twice as high in 2004 as in 1990. Source: Center for Medicare and Medicaid Services, "National Health Expenditure Web Tables," http://www.cms.hhs.gov/NationalHealthExpendData/downloads/tables.pdf.
} 
Helms et al (1978). Regarding pharmaceutical substitution, Balkrishnan et al. (2001) study the effects, in a Medicare HMO, of increased cost-sharing for prescription drugs and find a consequent $25.2 \%$ increase in inpatient admissions. Tamblyn et al. (2001) find that a reduction in "essential" drug use induced by a co-payment rise was associated with higher adverse events, such as hospitalizations. Duggan (2004) finds no substitution between anti-psychotic drugs and inpatient psychiatric care. Lichtenberg $(1996,2001)$ finds that differences in the quantity and type of drugs (induced by physician prescribing behavior) used by patients is correlated with differences in the use of other categories of health care --- patients who use more and newer drugs consume less inpatient care.

Two economic theories are relevant to the effects of the price of drugs on people's health and consumption of other types of health care. The household production model introduced by Becker (1965) provides a framework for analyzing the determinants of many behaviors including health-related behaviors. In this approach, prescription drugs are one of many inputs to a health production function. Drugs and other medical goods such as physician visits or hospital care are substitute (or complementary) treatments for some diseases. For example, clinical evidence suggests that either antidepressant medication or psychotherapy can be used as first line treatment for mild to moderate Major Depressive Disorder (MDD). Theory suggests that, to the extent that these other inputs are substitutes (complements) to drugs in producing health, increases in drug prices will result in increases (decreases) in the consumption of other medical goods.

Grossman's health capital theory (1972) is derived from Becker's basic model, and provides a dynamic framework for analyzing medical care demand. In this theory, individuals inherit an initial stock of health capital that depreciates over time and can be increased by 
investment. Gross investments in health capital are produced by inputs such as medical care, diet, exercise, etc. Prices of medical goods affect people's demand for medical care in each period. Thus, the effects of changes in input prices on consumers' demands for medical care may have a dynamic component through their effects on health capital.

Taken together, these theories suggest that changes in drug prices will have effects not only on the demand for drugs, but also on the demands for substitute and complementary services. They also suggest that there will be a dynamic aspect to the effects of changes in drug prices. Adjustment will not occur instantaneously, but over time. For example, if an increase in drug co-payments causes people to fall out of compliance with their drug therapy for hypertension, they may be more likely to suffer heart attacks, strokes, and other complications, leading to hospitalization, physician care, additional medication, and higher health care spending.

A fuller understanding of the effects of out-of-pocket drug price changes on health spending and health outcomes requires an examination of the dynamic structure of demand for health care services. This is our focus. We use a large panel dataset of health insurance claims and benefit design information to identify the effects on drug spending, outpatient spending, and inpatient spending of changes in workers' employer-provided prescription drug benefits.

This study differs from previous work by allowing for dynamic adjustment by consumers, explicitly controlling for selection (via fixed effects), using a large, national dataset, and addressing substitution between drugs and other types of health care using comprehensive measures of inpatient and outpatient quantity and spending.

There are two central findings. First, there is substantial substitution between prescription drug use and the use of outpatient care. Increases in out-of-pocket drug prices lead to decreases in the demand for drugs but lead to sizeable increases in demand and spending on outpatient care. 
We do not find detectable changes in inpatient spending as a result of increases in drug copayments. Second, we find strong dynamic own-price effects for drugs and dynamic substitution effects for outpatient care. The dynamic price effects are substantially larger than the contemporaneous effects. These results are striking and (to our knowledge) completely new.

The paper is organized as follows. Section 2 provides relevant institutional facts and findings from prior literature. The data used in the study are described in Section 3. Section 4 describes the empirical strategy, including estimation methods. Results are discussed in Section 5. Finally, Section 6 contains a summary and conclusions.

\section{Background}

Aggregate spending in the U.S. on outpatient prescription drugs has increased rapidly, both in absolute terms, and compared to the trends for spending on hospital services and physician services. Private drug spending has increased by 15-20 percent per year, starting in the $1990 \mathrm{~s}^{2}$ Prescription drug spending is the third largest component (after hospital and physician services) of national health care expenses at $\$ 162.4$ billion. This amount is almost 5 times as large as the amount spent in 1990, and drugs now account for more than $11 \%$ of total health care spending. ${ }^{3}$

In response to these rapid, large increases in drug expenditures, many employers and insurance plans adopted more stringent prescription drug benefit designs, imposing greater costsharing on patients for the use of prescription drugs. By far the most common form of costsharing for prescription drugs is a menu of fixed co-payments. Drugs are divided into groups called "tiers," and each drug in a given tier has the same co-payment. In a two-tier plan,

\footnotetext{
${ }^{2}$ Kaiser Family Foundation and Health Research and Educational Trust, Employer Health Benefits: 2004 Annual Survey, Sept 2004. http://www.kff.org/insurance/7148.cfm

${ }^{3}$ Source: Center for Medicare and Medicaid Services, "National Health Expenditure Web Tables," http://www.cms.hhs.gov/NationalHealthExpendData/downloads/tables.pdf.
} 
consumers pay a lower co-payment for generic drugs and a higher co-payment for branded drugs. In a three tier plan, a further distinction is made between "preferred" and "non-preferred" branded drugs. There is a higher co-payment for non-preferred drugs. A typical co-payment schedule for a 3-tier plan is a $\$ 5$ co-payment for each generic drug prescription, $\$ 10$ for preferred branded drugs, and $\$ 25$ for non-preferred branded drugs. Moreover, starting in the late 1990s insurance plans further differentiated the co-payments for drugs purchased at walk-in pharmacies ("card plan" purchases) and at mail order pharmacies. The mail order part of the plan typically requires that ninety days supply of the drug be purchased at once. Co-payments are set so that mail-order prescription purchases cost less per day than do card plan prescription purchases.

These changes have led to an increase in out-of-pocket payments by consumers over time. According to statistics from the Kaiser Family Foundation, ${ }^{4}$ the average co-payment for generic drugs increased from $\$ 7$ per prescription in 2000 to $\$ 11$ (a 57\% increase) in 2006 for workers with employer-sponsored health plans. Co-payments for preferred branded drugs increased from $\$ 13$ to $\$ 24$ (an 85\% increase) per prescription from 2000 to 2006, and non-preferred drugs increased from $\$ 17$ to $\$ 38$ (a $124 \%$ increase) per prescription over the same period. Recently, a few drug plans (about 5\%) have included a fourth tier of drugs, and in 2006, the average price in that tier was $\$ 63$. Finally, these estimates understate the true increase in average out-of-pocket costs, since, over time, drug plans have been increasing both within-tier prices and the number of tiers. For example, in 2000 the distribution of workers among one-tier, two-tier, three-tier, and four-tier plans was $22 \%, 49 \%, 27 \%, 0 \%$, respectively, with $2 \%$ in other types of plans. In 2006 , the distribution was $8 \%, 16 \%, 69 \%, 5 \%$, with $2 \%$ in others.

\footnotetext{
${ }^{4}$ Kaiser Family Foundation, Employer Health Benefits 2006 Annual Survey, section 9. http://www.kff.org/insurance/7527/index.cfm
} 


\section{Data}

We use data from the Medstat MarketScan database. MarketScan is the largest private sector health care database in the U.S, containing paid claims of more than 7 million privately insured individuals, and over $\$ 13$ billion in annual healthcare expenditures. Medstat contracts with over 40 large employers for the submission of health insurance data for their employees. Neither employers nor health plans are identified by name in the database. The database contains longitudinal data for each person, including person and family identifiers, enrollment history, use of inpatient care, outpatient care and prescription drugs, health expenditure, and detailed health insurance coverage information.

We link information from five different files in the Medstat database from 1997-2003: 1) the enrollment file, containing patients' demographics and detailed information on their health plan enrollment history, 2) the employer benefit plan design file, containing summary benefit descriptions for major medical and prescription drugs benefits for many health plans, 3) the hospital inpatient claims file, containing individual hospital claims aggregated to the level of the hospital stay and providing information on diagnosis, treatment, length of stay, and basic payment information, 4) the outpatient service claims file, containing individual outpatient claims aggregated to the level of each outpatient visit with information on diagnosis, treatment procedures and payment information, and 5) the outpatient pharmaceutical claims file, containing a claim for each prescription filled by each person with information on days of prescription drug supplied, national drug codes, therapeutic classes and payment information. 


\subsection{Sample Selection}

Each year from 1997-2003, more than 40 individual employers contribute data to the MarketScan databases, and around 60 have contributed over that time. However, not every employer submitted all five files to Medstat in a given year. We use only firms with complete information in all of the above five files. Moreover, in our empirical work, we estimate models with dynamic price effects (1 lag), and person-specific fixed effects. This requires at least three consecutive years of full information. Therefore, we selected from the overall database firms which had complete information from all of the five files mentioned above for at least three consecutive years. This removed a large number of firms from our analysis, principally because a large number of firms did not submit prescription drug data. For example, in 1997 only 19 out of 53 employers submitted prescription drug claims data; in 2000, only 24 out of 45 employers submitted drug data; and in 2003, 38 out of 45 employers submitted drug data. After applying the 3-consecutive-year requirement, 16 employers remain.

Of these 16 employers, two used coinsurance in their prescription drug benefits design and the other 14 used co-payments as their cost-sharing mechanism. Since these two cost-sharing mechanisms represent different incentive strategies in insurance benefit design, and have different effects on the demand for medical care, we limit our analysis to the fixed co-payment insurance plans, which represent the most common benefit design for pharmaceuticals (Kaiser, 2006). Last, the employer benefit plan design file contains some missing or inaccurate information for prescription drug benefits or medical benefits for some employers. We delete the firms with unclear or missing insurance benefits information from our analysis sample, an additional three firms. 
There are eleven employers which have three consecutive years of full information, clear insurance benefit information, and use co-payments as their cost-sharing mechanism for prescription drugs. These employers offer multiple insurance plans of varying generosity. Of these eleven firms, nine had a single, uniform prescription drug benefit plan: that is, all employees faced identical prescription drug plans at any given time. We focus on the plans at these nine employers. For consumers covered by these firms, any change in consumer out-ofpocket price for prescription drugs results not from employees switching drug plans to change their own out of pocket benefits, but from employers uniformly changing the benefits of all of their employees. This selection strategy left us with 97 insurance plans from nine large employers. ${ }^{5}$

On average there are 4.3 years of data from each firm. There are in total 1,304,687 individuals who have ever enrolled at least one full year in these nine firms. We further restrict our selection of individuals by examining only those individuals who have been continuously enrolled for at least three years during the 1997-2003 period. ${ }^{6}$ This selection criterion rules out about $56 \%$ of individuals. Last, people older than 65 are excluded because of the complexities introduced by Medicare coverage, potential outside Medigap coverage, and coordination of benefits issues. Finally, we have a panel data set of $1,713,879$ person-years for 526,086 people in 97 different insurance plans at nine different employers, spanning a seven-year period from 1997 to 2003 .

Given all of the observations eliminated by the inclusion criteria, there is a natural concern about the representativeness of the data in the analysis sample. We therefore make a number of

\footnotetext{
${ }^{5}$ Including the two firms which have non-identical prescription drug benefits in a given year doesn't change the main results of this paper.

${ }^{6}$ Continuously enrolled here means continuously enrolled in any of the firm's health plans. We are not dropping people who switch among health plans.
} 
comparisons of the analysis sample with the full sample from the Medstat database and the population in the U.S. with employer sponsored health insurance.

In Figures 1 through 4, we compare demographic and spending variables for people in our analysis sample with the full sample in the Medstat database and with the employer-insured U.S. population. We get information on age, regional, annual total medical spending, and annual pharmaceutical spending for the employer-insured U.S. population from the Medical Expenditure Panel Survey from 1997 - 2003. Figure 1 suggests that the age distribution in the Medstat sample (excluding those aged greater than 65) represents the U.S. population well, except that it underrepresents the age group $25-44$ by $6.8 \%$, and overrepresents the age group 55 64 by 4\%. The same conclusion holds for the comparison of our analysis sample with the U.S. population - our sample is slightly older. The Medstat sample and our analysis sample are less representative in terms of regional distribution compared with the U.S. population. The South region is over-represented in these two samples, and Northeast and West are under-represented. This is described in Figure 2.

Figures 3 and 4 indicate that the three samples follow similar trends in per-capita total spending and pharmaceutical spending, but enrollees in the Medstat sample on average spend $\$ 146$ more for prescription drugs, and $\$ 300$ more for all types of medical care. For our analysis sample, enrollees on average spend $\$ 380$ more for prescription drugs, and $\$ 945$ more for all types of medical care, compared to an average employer-insured person.

One might wonder to what degree differences in spending between our analysis sample and the U.S. population arise from differences in price and to what degree from differences in quantity. Consider the line labeled "United States, adjusted" in Figure 3. This line shows what the average drug spending in the MEPS, employer-covered sample would have been, had 
individuals in the MEPS sample paid the same drug prices which were paid in the same year, on average, by the members of the Medstat population. That is, we calculated (at the NDC level) average payments for each drug in each year in the Medstat data and applied these prices to the quantities purchased in the MEPS. Obviously, this adjustment did approximately nothing to drug spending in the MEPS, from which we conclude that differences in drug spending in the two samples arise primarily from differences in drug quantity.

Similarly, Figure 5 shows the differences in the number of inpatient days per capita between our analysis sample and the MEPS sample. This measure also shows that our analysis sample is sicker. Owing to potential differences in definitions and organization of the outpatient data, we did not perform a similar comparison on those data.

We also examined differences in the "incidence" of several important health conditions in each of the MEPS sample and our analysis sample: heart disease, stroke, hypertension, highcholesterol, asthma, and diabetes. The incidence measures are inferred from the inpatient and outpatient claims data in each sample by the relevant ICD-9CM diagnosis codes. A person is defined as incident with the named condition in one year if there was any relevant diagnosis code in that year. ${ }^{7}$ For each condition in each year, incidence is higher in our sample than in the MEPS sample. We present Figure 6, showing the combined incidence of the five conditions.

\footnotetext{
${ }^{7}$ Note that we didn't use initial diagnoses for our incidence measures, therefore our measures are not really incidences as that term is conventionally understood.
} 


\subsection{Measures}

Our dependent variables are quantity and total spending on prescription drugs, outpatient care, and inpatient care. For prescription drugs, quantity is the sum of days supplied from all prescriptions filled from a particular year for a patient. ${ }^{8}$ Similarly, quantity of outpatient services is the total number of outpatient visits, and the quantity of inpatient services is the total number of inpatient admissions. ${ }^{9}$

Total spending on prescription drugs, outpatient services and inpatient services are calculated as the yearly spending per enrollee. This measure of spending is the sum of spending by the insurer in the database and the required out-of-pocket spending by the insured person. We are not able to observe whether or not the consumer actually made their out-of-pocket payment, neither are we able to observe the operations of coordination of benefits.

Since we use an individual fixed effects (hereafter FE) model in our estimation, only timevarying socio-demographic variables are used. The effects of time-constant variables such as race, sex, education, etc. are absorbed in the individual FE. In our estimation, we use indicators of retirement status, a set of individual FE, and a set of year FE. Because we enter both individual and year FE, we cannot also enter age into our estimating equations. We do wish, however, to allow spending to grow at different rates for people in different age groups; therefore, we construct a set of interactions between dummies for age category and a linear time trend. We separate people into seven age categories: 0-10 years, 11-18, 19-29, 30-39, 40-49, 50-59, and 6064.

Our primary independent variable of interest is the out-of-pocket price faced by consumers for prescription drugs. In the presence of health insurance, the prices faced by a consumer for

\footnotetext{
${ }^{8}$ Our results are similar if we define quantity as the number of prescriptions filled.

${ }^{9} \mathrm{We}$ also ran the analysis using inpatient days as the quantity measure and obtained similar results.
} 
health services are determined by the consumer's health plan benefit design. Ideally, one would like to include all the relevant aspects of the prescription drug benefit design in the analysis. There are six variables describing the benefit design in the Medstat database (generic copayment, preferred brand co-payment, and non-preferred brand co-payment, separately for card and mail order). While this is a rich source of descriptive information, these measures are highly collinear; therefore, it isn't possible separately to identify their effects in a regression. Further, there are 18 changes in drug benefit design that occur in the data, making it highly unlikely we could identify parameters for six variables describing the drug benefit (see Table 2).

Thus, we construct an out-of-pocket price index for prescription drugs for each health plan in each year. For each plan-year, the price index is a weighted average of the out-of-pocket copayments for that plan's tiers: the generic co-payment, the preferred brand co-payment, and the non-preferred brand co-payment. For a plan with only two tiers, we use that plan's brand copayment as both the preferred and non-preferred brand co-payment. In addition, since plans often specify different co-payments for the card plan and the mail order plan, we differentiate between those two modes of delivery in the price index. The formula for the price index for plan $\mathrm{j}$ in time $\mathrm{t}$ is:

$$
\begin{aligned}
& P_{j}^{t}=\operatorname{Copay}_{j, G}^{t, \text { Card }} * W_{\text {Card }, G}+\operatorname{Copay}_{j, P B}^{t, \text { Card }} * W_{\text {Card,PB }}+\text { Copay }_{j, N P B}^{t, \text { Card }} * W_{\text {Card, NPB }} \\
& + \text { Copay }_{j, G}^{t, \text { Mail }} * W_{\text {Mail, },}+\text { Copay }_{j, P B}^{t, \text { Mail }} * W_{\text {Mail,PB }}+\text { Copay }_{j, N P B}^{t, \text { Mail }} * W_{\text {Mail,NPB }}
\end{aligned}
$$

Copay $_{j, G}^{t, \text { Card }}$, Copay $_{j, P B}^{t, \text { Card }}$ and Copay ${ }_{j, N P B}^{t, \text { Card }}$ are plan $j^{\prime} s$ co-payments for one prescription of generic drugs, preferred brand drugs and non-preferred brand drugs, respectively, purchased using an insurance card at walk-up pharmacies. $\operatorname{Copay}_{j, G}^{t, \text { Mail }}, \operatorname{Copay}_{j, P B}^{t, \text { Mail }}$ and $\operatorname{Copay}_{j, N P B}^{t, \text { Mail }}$ are plan j's co-payments for one prescription of generic drugs, preferred brand drugs and non-preferred 
brand drugs, respectively, purchased by mail order. The $W_{m, n}$ are quantity-based weights for generic, preferred brand and non-preferred brand drugs for card and mail-order purchases, calculated using prescription drug claims data for all the enrollees in all the years in the nine study firms. For example, the weight on generic, mail-order, $W_{\text {Mail, },}$, is the proportion of prescriptions in our whole sample (all firms and years) which are generic drugs ordered by mailorder.

Table 1 contains the weights for the six categories. For example, the table shows that $W_{\text {Mail,G }}$, the weight on generic mail-order co-payment, is 0.0603 , meaning that $6.03 \%$ of all prescriptions in our data are for generics and filled at a mail-order pharmacy. Since each employer in our data offers a uniform prescription drug benefit at any given time, this price index changes for a consumer only when his employer changes its prescription drug benefit design.

Because of the potential for input substitution in the production of health, the demand equations for each type of medical care are functions of drug prices and the prices of other medical services. Insurance benefits for outpatient and inpatient services are more complicated than are those for prescription drugs. Common cost-sharing devices for medical services take the form of a combination of deductibles, coinsurance rates for spending above the deductible, a copayment for one physician office visit, and a stop-loss limit beyond which consumers don't pay any more. The budget sets for these medical services are therefore complicated and nonlinear. It is difficult to construct a single price measure for these services that would correctly reflect the true out-of-pocket prices consumers pay. Instead we include the deductible for medical services and the co-payment for outpatient visits as our out-of-pocket price measures for medical services. 
Table 2 provides a description of the history of prescription drug benefits for the nine firms, and the drug price index for the health plans within each employer. Each firm changed its prescription drug benefits at least once, with a total of 18 price changes occurring during the 1997-2003 period. Because of this, there is no "control group" of firms with no drug plan changes over our sample period.

As is clear in Table 2, each benefit change is an increase in co-payments and therefore made the prescription drug insurance less generous. This is consistent with the national trend of increasing drug co-payments over the past decade. In Figure 7 we compare the average copayments for generic, preferred branded, and non-preferred branded drugs of the nine firms in our study with those of the employer-sponsored prescription drug insurance plans for the U.S. population. The estimates of drug co-payments for the U.S. population are from the Employer Health Benefits Annual Surveys conducted by the Health Research and Educational Trust (HRET) in 2000-2003. ${ }^{10}$

Table 3 gives definitions of all the variables used in the demand estimation, and Table 4 provides summary statistics of these variables. Our dependent variables are the spending and use variables for prescription drugs, outpatient care, and inpatient care. We construct the total spending variable as the sum of spending on these three types of medical care. In Table 4 we also report the number of observed zeroes in the corresponding quantity and spending variables. In our sample, $96 \%$ of the person-years see no inpatient admissions, compared to $30 \%$ for prescription drug use, and $17 \%$ for outpatient care. In this sample $87 \%$ of individuals never used any inpatient care during the time span when data are available for them, compared with $13 \%$ for

\footnotetext{
${ }^{10}$ The Employer Health Benefit Annual Survey is funded by the Kaiser Family Foundation and studied jointly by HRET and the Kaiser Family Foundation since 1987. It collects health insurance benefits information of approximately 2,000 randomly selected employers in all major industries. See http://www.kff.org/insurance/ehbsarchives.cfm for details.
} 
prescription drugs and $6 \%$ for outpatient care. We describe our empirical strategy for coping with the large number of zero values in the next section.

By construction, there is no switching within employer among drug plans, since all of our employers have uniform drug plans over time. But switching among medical plans is still of potential concern. Employers have, on average in our data, 2.76 medical plans available to their employees. Table 5 presents insurance plan switching rates for each firm. This table shows that switching rates are small. One might interpret the low switching rates in Table 5 as indicating that, although people may self-select into insurance plans, it seems that these selections are determined mostly by stable health or preference factors at the baseline year. If this is true, the individual FE will largely account for unobservable factors which drive selection.

\section{Empirical Strategy}

\subsection{Model Specification}

We estimate equations relating the demand and total spending on prescription drugs, outpatient care, and inpatient care to the out-of-pocket prices paid by consumers for drugs and to the medical plan design characteristics. The basic estimation model is

$$
Q_{i t}^{j}=\beta_{1}^{j}+\beta_{2}^{j} P_{i t}^{d}+\beta_{3}^{j} P_{i t-1}^{d}+\beta_{4}^{j} P_{i t}^{m}+\beta_{5}^{j} P_{i t-1}^{m}+X_{i t} \delta^{j}+\alpha_{i}^{j}+\gamma_{t}^{j}+\varepsilon_{i t}^{j}
$$

In this equation $Q_{i t}^{j}$ denotes the demand for health input $j$ by person $i$ in period $t$, where $j$ indexes prescription drugs, outpatient care, and inpatient care. The variables $P_{i t}^{d}, P_{i, t-1}^{d}$ are indexes of the contemporaneous and lagged patient out-of-pocket prices for prescription drugs and $P_{i t}^{\mathrm{m}}, P_{i, t-1}^{\mathrm{m}}$ stand for prices for other types of medical care, such as outpatient and inpatient care. The $X_{i t}$ capture all non-price time-varying variables that also affect demand for medical 
care, such as retirement status and age group-year interactions. The error term can be decomposed into three separate elements. The term $\alpha_{i}^{j}$ captures unobservable and unchanging individual heterogeneities in medical demand, such as individuals' preferences for using medical goods, inherited traits, etc. The term $\gamma_{t}^{j}$ captures the general trend effects in demand over time, and $\varepsilon_{i t}^{j}$ stands for all other random factors which might affect demand.

Since we are concerned with the dynamic effects of out-of-pocket drug prices on both drug demand and demand for other medical services, throughout our analysis we include both the current drug price index and one lag of the drug price index. In this model, the "long-run" effect of a change in out-of-pocket prescription drug prices is the sum of the effects of both the contemporaneous and lagged price variables. We are unable to include a lag structure longer than 1 year, since this would require including only firms with four or more years of usable data, and this would reduce our sample size substantially. ${ }^{11}$

The spending measure we use throughout is the total spending on the relevant service. For example, total spending on drugs is the consumer's out-of-pocket spending plus the insurance plan's spending, subject to the caveats above. It is important to distinguish our regression of total spending on price from the more familiar expenditure function approach to estimating demand. Our total spending regressions are not expenditure function regressions because the left-handside spending variable is not the consumer's total spending but the consumer's total spending plus the plan's total spending. Therefore, our price elasticity of spending is not the consumer's price elasticity of demand plus one, as it is in consumer theory. The spending variable here is more like a quantity index: it weights each prescription by the total (as opposed to out-of-pocket) price paid for the prescription.

${ }^{11}$ Adding two lags in the regression causes the loss of three of nine firms. The total number of individuals falls to 355,920 from 526,086 . 


\subsection{Econometric Issues}

Throughout the analysis, we use FE to control for unobserved individual characteristics. This choice is motivated by several considerations. The consumer-specific information we have access to is quite sparse. For example, we have no income information and the only health status information we have is that which we can infer from the claims data. ${ }^{12}$ Second, though there is little switching among medical plans over time, there is still the prospect of adverse selection: consumers may already have selected into their health plans at baseline. Thus, we hope to control for unobserved consumer characteristics and to mitigate adverse selection by including individual FE. Since firm FE are contained in the span of the individual FE, using this strategy means that we are identifying the effects of the out-of-pocket drug prices solely from the variation induced by changes in the drug plans within a firm over time.

Over our sample, firms change not only the design of their drug benefits, but also the design of their other medical benefits (co-payments, deductibles, etc). In addition, a small number of employees switch from one medical plan to another over time. We include controls for the non-drug design characteristics of the health plans in all our regressions to deal with this, but, if changes in non-drug health plan design always or nearly always accompanied changes in drug plan design this would still be cause for concern. In Table 6, we present a contingency table showing the joint distribution of drug plan design changes and non-drug plan design changes. Of the 34 firm-years ${ }^{13}$ in the analysis, 18 featured drug plan design changes and 12 featured non-drug benefit plan design changes. Non-drug benefit changes appear slightly more likely to occur when drug benefits change ( $43 \%$ vs. $31 \%$ ); however, this relationship is not

\footnotetext{
${ }^{12}$ We could attempt to estimate health status from the claims data by using a "before" period. However, that would require shortening our panel, which would compromise the estimation of dynamic effects and make controlling for other aspects of unobserved individual heterogeneity more difficult.

${ }^{13}$ There are 43 firm-years of data. Since we are analyzing changes in benefits, we must omit the first year of data for each of the 9 firms.
} 
significant at conventional levels ( $p=0.6$ ) and the correlation between the two change dummy variables is 0.08 .

We use linear FE models for both the quantity and expenditure equations. This approach is straightforward; however, there are a number of econometric issues associated with the use of linear FE estimators, given the nature of some of our data. The measures of quantity are counts, and some of the expenditure variables have significant probability mass at zero. We therefore also employ a FE count data model and a FE Tobit model to estimate the quantity and spending equations, respectively.

The errors in the demand equations are likely to be serially correlated when the individual FE and time trends do not completely control for the persistence in consumer's demand. We therefore use the block bootstrap method (with blocking at the individual level) to adjust standard errors for serial correlation and heteroskedasticity.

There is a potential for mean reversion to affect our results. If firms change their benefit designs in response to unusually high spending and if spending mean reverts, then we could see falling spending following a change in benefit plan design in the absence of a true effect of benefit plan design on spending. In the results section, we'll briefly discuss how this potential problem could affect our estimation results. 


\subsubsection{Fixed Effect Count Data Model}

As Table 3 documents, our quantity variables are counts and, as Table 4 shows, some of them are frequently zero. We therefore use FE count data methods to model them.

Specifically, we use Hausman, Hall and Griliches' (1984) conditional maximum likelihood estimator (HHG). The HHG estimator is based on a conditional mean assumption, $E\left(Q_{i t}^{j}\right)=\exp \left(\alpha_{i}^{j}+X_{i t} \beta^{j}\right)=\exp \left(\alpha_{i}^{j}\right) \exp \left(X_{i t} \beta^{j}\right)$, where the FE takes the multiplicative form $\exp \left(\alpha_{i}^{j}\right)$. Estimation is fairly straightforward, since the individual FE parameters $\alpha_{i}^{j}$ are conditioned out in the log-likelihood function. This estimator also has strong robustness properties. Consistency requires only that the conditional mean assumption is correct. Except for the conditional mean, the distribution of $y_{i t}$ given $\left(\alpha_{i}, x_{i t}\right)$ is completely unrestricted. That means the estimates are consistent even in the presence of overdispersion, underdispersion, or serial correlation (Wooldridge, 1999).

\subsubsection{Fixed Effect Tobit Model}

It would be inappropriate to use linear regression models for the spending variables, given the large number of zeros observed for each. Obviously, these zeroes arise when consumers do not use any of the services in the relevant category in a year. ${ }^{14}$ We therefore use FE Tobit models to estimate the parameters of the spending models.

Although there has been a large literature on identification and estimation of linear panel data models with FE, fixed effect limited dependent models have not been studied as much. Honoré (1992) proposed a semi-parametric estimator for the FE Tobit model. The idea for this

\footnotetext{
${ }^{14}$ The large number of zeros in conjunction with a fixed-effects approach also poses problems for the commonlyemployed "two-part" model of health spending. With fixed effects, any person who either used a service in every year or who never used a service is dropped from the first part (the probit for used/not-used) of the two-part model.
} 
estimator is to restore the symmetry of the distribution of the dependent variable which was destroyed by censoring. In a panel data context, the censored regression model can be described by

$$
\begin{aligned}
& y_{i t}^{*}=x_{i t} \beta+\alpha_{i}+\varepsilon_{i t} \\
& y_{i t}=\max \left\{0, y_{i t}^{*}\right\}
\end{aligned}
$$

Honoré (1992) proposed that under the assumption of independent and identically distributed errors $\left(\varepsilon_{i t}, \varepsilon_{i s}\right)$, where $t, s$ denotes errors in different periods, the conditional distribution of $\left(y_{i t}^{*}, y_{i s}^{*}\right)$ given $\left(x_{i}, \alpha_{i}\right)$ is distributed symmetrically around the $45^{\circ}$-degree line through $\left(x_{i s} \beta, x_{i t} \beta\right)$ (or equivalently through the $45^{\circ}$-degree line through $\left.\left(\left(x_{i s}-x_{i t}\right) \beta, 0\right)\right)$. As discussed in Honoré (2000), this i.i.d. error assumption can be relaxed, and the estimator is still consistent under only conditional exchangeability and conditional stationarity assumptions. As this is true for any value of $\alpha_{i}$, it is also true for the conditional distribution of $\left(y_{i t}^{*}, y_{i s}^{*}\right)$ given $x_{i}$.

Honoré proposed two estimators - the trimmed least absolute deviation estimator (LAD) and trimmed least square estimator (LS) - for FE Tobit models. These two estimators are essentially the generalization of Powell's (1984) least absolute deviation estimator and Powell's (1986) trimmed Least Square estimators for censored regressions, in the setting of panel data with FE. Each estimator is consistent and asymptotically normal under fairly weak assumptions. Moreover, these estimators do not impose any parametric structure on the distribution of error terms.

As later pointed out by Deaton (1997), Powell's $(1984,1986)$ censored LAD estimator and censored least square estimator can be calculated easily by the repeated application of linear least squares or least absolute deviations regression algorithms. This point was further reinforced by Chay and Powell (2001). Simply put, these estimators can be achieved by iterating between the 
"symmetric trimming" of the dependent variables using estimates from the previous iteration and least squares or median regression using the "trimmed" data. To derive our FE Tobit estimates, we use the identically censored least squares (ICLS) estimator of Honoré as described by Chay and Powell (2001).

\subsubsection{Serial Correlation in Panel Errors}

Estimating health care demand using longitudinal data is subject to a potential serial correlation problem. Several studies show that consumers' health spending is persistent from one year to the next (Eichner, McClellan and Wise, 1996; Vliet, 1992; Pauly and Zeng, 2003) and that there is habituation in drug prescribing and use (Coulson and Stuart, 1992; Hellerstein, 1998; Coscelli, 2000). We use the block bootstrap method to correct our standard errors for serial correlation. The block bootstrapping is done at the individual consumer level, so that we are correcting for serial correlation and heteroskedasticity at this individual level, and we use 250 replications in all cases. Since we have to drop one year of data because of the lagged prices, our panel data has small $\mathrm{T}$ ( 3.3 on average per person) and large $\mathrm{N}(526,086)$, in which setting Bertrand, Duflo and Mullainathan (2002) find the bootstrap to be a good choice. The bootstrap has the merit of avoiding strong parametric assumptions about the structure of the error variance matrix. The serial correlation problem and possible solutions to it for nonlinear panel models, such as FE Poisson models and FE Tobit models which we will estimate in this study, are still not fully explored in theory. 


\section{Results $^{15}$}

Figure 8 shows the time series movements of per-capita prescription drug spending and average out-of-pocket prices for prescription drugs over the study period, 1997-2003. These drug prices are the weighted average of yearly pharmaceutical price indexes at the firm level. Over this period, both the average co-payment and the average spending per enrollee have increased. ${ }^{16}$ Furthermore, the correlation over time between detrended average co-payment and detrended average spending is $0.38(\mathrm{~N}=7)$ and the OLS regression coefficient from a regression of spending on co-payment and a time trend is 48.33 (also $\mathrm{N}=7$ ).

Table 7 summarizes the FE estimation results for the spending equations, and Table 8 summarizes the FE results for the quantity equations. In Table 7, we present results from individual linear FE models and FE Tobit models. In Table 8 we present results from individual linear FE models and FE Poisson models. For each model in Table 7 and Table 8, we present results from both a "static" specification in which only contemporaneous drug and medical benefit design variables are included and from a "dynamic" specification in which both contemporaneous and once lagged drug and medical benefit design variables are included.

In each table, point estimates of average marginal effects are reported. The parameter significance indicators are based on block bootstrapped standard errors which cluster residual errors at the individual level. For each demand variable only the coefficients of contemporaneous and lagged drug prices are reported. The estimates of the coefficients for the control variables are available from the authors upon request.

\footnotetext{
${ }^{15}$ The fixed-effect Tobit results for the inpatient equation presented here are different from results presented in earlier versions of the paper because we discovered and corrected programming errors in our implementation of the estimators.

${ }^{16}$ Using median medical spending, median drug spending, and median co-payment results in qualitatively similar graphs.
} 
The coefficients for prescription drug demand yield consistent results through all specifications. Increases in out-of-pocket drug prices cause fewer days of drug use and reduce spending on drugs. For example, the individual FE Tobit estimates in the dynamic model suggest a $\$ 1$ increase in drug price reduces total drug spending by $\$ 23.62$ in the first year after the price change, and a further reduction of $\$ 8.95$ in the second year after the price change. This corresponds to a "short-run" elasticity of -.6 and "long-run" elasticity of - .8 for drug spending. The regression results for days of drug supply follow a similar pattern. The static model shows smaller effects, with an estimated own-price elasticity of -0.5 . These results are consistent with previous findings that more stringent drug cost-sharing benefits are associated with reductions in drug use and drug spending. Based on our calculations, Joyce et al (2002) find drug spending elasticities of co-payment of between -0.2 and -0.3 while Balrishkan et al (2001) find an elasticity of $-1.27 .^{17}$

One distinguishing aspect of our analysis is the examination of dynamic effects in demand. The results from our study show that there are significant and strong lagged price effects on the demand for drugs. These results suggest that there are substantial adjustments to drug consumption in the long term, along with considerable shorter term stickiness.

Through all specifications, results from both the OLS and Tobit estimations suggest that consumers facing higher drug co-payments substitute to outpatient services in both the short and long-run. Specifically, from the dynamic, individual FE Tobit results in Table 7, a one dollar increase in the out-of-pocket drug price index increases per-capita outpatient spending by $\$ 6.41$ in the first year and $\$ 15.82$ in the second year after the price changes (i.e. a further increase of \$9.41). These estimates correspond to "short-run" and "long-run" cross-price elasticities of 0.1 and 0.2 , respectively.

\footnotetext{
${ }^{17}$ Other papers in the literature did not have easily computable elasticities.
} 
The FE Poisson results in Table 8 indicate that a one dollar increase in the out-of-pocket drug price index leads to 0.026 fewer outpatient visits in the first year, but 0.075 more outpatient visits in the second year after the price change. These correspond to short-run and long-run cross-price elasticities of -0.02 and 0.07 with drugs, respectively. One limitation associated with the measure of the number of outpatient visits variable is that outpatient visits are not homogeneous. An outpatient surgery counts the same as a physician office visit.

The results for inpatient care suggest no measurable relationship between drug prices and inpatient spending and a small relationship between drug prices and inpatient quantity. Observe that no inpatient coefficient in Table 7 is significant, either statistically or economically. In Table 8, lagged drug prices seem to have a small, negative effect on inpatient admissions. The effect of increases in out-of-pocket drug prices on overall spending is smaller than the effect on drug spending. A $\$ 1$ increase in out-of-pocket drug price reduces total spending by $\$ 20.88$ in the first year and a further $\$ 0.35$ in the second year, with only the contemporaneous effect achieving statistical significance. Thus, the long-run drop in total spending, $\$ 21.23$, is about $65 \%$ of the long-run drop in drug spending, $\$ 32.57$.

It is worth noting that the OLS results are very similar. A $\$ 1$ increase in drug copay reduces drug spending by $\$ 20.34$ in the first year and $\$ 33.83$ in the second, while total spending falls by $\$ 13.51$ in the first year and $\$ 19.27$ in the second. The long-run total expenditure savings is therefore about $60 \%$ of long-run drug expenditure savings.

As discussed in section 4.2, our results could potentially affected by the mean reversion problem. In our context, since all changes in drug benefit plan design are toward less generosity, this would likely lead us to overestimate the effect of price on drug demand. Presumably, this effect would also lead us to underestimate the effect of drug price increases on inpatient and 
outpatient demand --- since demand for these services would fall (for mean reversion reasons) after an increase in drug prices.

In Tables 9 and 10, we present an analysis which separates individuals according to whether or not they have a chronic condition. Specifically, we identify all individuals who have a diagnosis code indicating hypertension, high cholesterol, or asthma as chronically ill. Table 9 shows descriptive statistics stratified by chronic illness status, and, as one would expect, chronically ill people are older and spend more on health care. In Table 10, we present the results of separate FE regressions stratified according to chronic illness status. In each category, the qualitative results are the same. Increasing drug out-of-pocket payments lowers drug spending and lowers total spending. The absolute magnitude of the effects is larger for the chronically ill group.

The decrease in total spending is lower than the decrease in drug spending in each group. For the chronically ill group, the long-run reduction in drug expenditures is $\$ 56.31$ while the long-run reduction in total expenditure is $\$ 53.23$ (95\% of the long-run drop in drug expenditures). For the non-chronically ill, the long-run reduction in drug expenditures is $\$ 17.10$ while the longrun drop in total expenditures is $\$ 4.89$, only $29 \%$ of the drop in drug expenditures. In addition, the substitution towards outpatient care seems to be larger in absolute magnitude but similar in percentage terms among the chronically ill.

\section{Summary and Conclusions}

We estimate consumers' responses to pharmaceutical cost sharing, accounting for the contemporaneous and lagged responses of drug, outpatient, and inpatient quantity and spending to increases in drug co-payments. Our results show that increased consumer cost sharing for 
prescription drugs reduces both use of and spending on prescription drugs. We also find dynamic adjustment by consumers: the effects one year after a co-payment increase are substantially larger than the contemporaneous effects. We also find that consumers substitute to outpatient care in response to rising drug prices. These effects also have a significant dynamic component: there is substantially more substitution to outpatient care one year after an increase in pharmaceutical cost sharing. There is no significant substitution between drugs and inpatient care.

In total, we find that the expenditure savings on prescription drugs are substantially offset by increases in outpatient spending. A $\$ 1$ increase in drug price reduces drug spending by $\$ 23.62$ in the first year after the price change and by $\$ 32.57$ in the second. Total spending falls by $\$ 20.88$ in the first year and $\$ 21.23$ in the second. Thus, in the long-run, total spending falls by about $65 \%$ as much as does drug spending, i.e., $35 \%$ of the savings achieved by reductions in drug spending are offset by consequent increases in other medical spending. Higher drug copayments save money on drug spending, but cost money on outpatient and possibly inpatient spending and have smaller effects on overall spending. The findings from our study suggest that high consumer cost-sharing may not be as effective a mechanism for controlling spending as has previously been thought. 


\section{References:}

Balkrishnan, R., Wesley, B.G., Fabian C.T., Shrestha A., and Anderson R.T., "Effect of Prescription Benefit Changes on Medical Care Utilization in a Medicare HMO Population”, American Journal of Managed Care, November 2001, Vol. 7, No. 11, 1093-1100.

Becker, G.S., “A Theory of the Allocation of Time”, Economic Journal, September 1965, Vol. 75, No. 299, 493-517.

Bertrand, M., Duflo, E. and Mullainathan, S., "How Much Should We Trust Difference-inDifference Estimates?”, Working Paper No. 8841, National Bureau of Economic Research, Cambridge, MA, March 2002.

Bhargava A., Franzini L. and Narendranathan W., "Serial Correlation and the Fixed Effect Model", Review of Economic Studies, October 1982, Vol. 49, No. 4, 533-549.

Buchinsky, M., "Changes in the U.S. Wage Structure 1963-1987: Application of Quantile Regression”, Econometrica, March 1994, Vol. 62, No. 2, 405-458.

Chay, K.Y. and Powell, J.L., "Semiparametric Censored Regression Models”, Journal of Economic Perspectives, Fall 2001, Vol. 15, No. 4, 29-42.

Cohen, J., "Medicaid Policy and the Substitution of Hospital Outpatient Care for Physician Care", Health Services Research, April 1989, Vol. 24, No.1, 33-66.

Coscelli, A., “The Importance of Doctors' and Patients' Preference in the Prescribing Decision”, Journal of Industrial Economics, September 2000, Vol.48, No. 3, 349-369.

Coulson, E.N. and Stuart, B., "Persistence in the Use of Pharmaceuticals by the Elderly. Evidence from Annual Claims", Journal of Health Economics, October 1992, Vol. 11, No.3, 315-328.

Davis, K. and Russell, L.B., "The Substitution of Hospital Outpatient Care for Inpatient Care", Review of Economics and Statistics, May 1972, Vol. 54, No. 2, 109-20. 
Deaton, A. and Muellbauer, J., Economics and Consumer Behavior, Cambridge University Press, Cambridge, U.K., 1980.

Doerpinghaus, H.I., "Effect of Ambulatory Surgery Policy Provisions on Medical Expense Insurance Claims", Journal of Risk and Insurance, December 1990, Vol. 57, No. 4, 608-622.

Dor, A. and Encinosa, W., "Does Cost Sharing Affect Compliance? The Case of Prescription Drugs", Working Paper No. 10738, National Bureau of Economic Research, Cambridge, MA, September 2004.

Efron B. and Tibshirani R., "Bootstrap Methods for Standard Errors, Confidence Intervals, and Other Measures of Statistical Accuracy”, Statistical Science, February 1986, Vol. 1, No. 1, 54-75.

Eichner, M.J., McClellan, M.B. and Wise, D.A., "Insurance or Self-insurance?: Variation, persistence, and Individual Health Accounts", Working Paper No. 5640, National Bureau of Economic Research, Cambridge, MA, June 1996.

Goldman, D.P., Joyce, G.F., Escarce, J.J., Pace, J.E., Solomon M.D., Laouri, M., Landsman, P.B., and Teutsch, S.M., "Pharmacy Benefits and the Use of Drugs by the Chronically Ill", JAMA: The Journal of the American Medical Association, May 2004, Vol. 291, No.19, 2344-2350.

Greene, W.H., Econometric Analysis, $5^{\text {th }}$ Edition, Prentice-Hall, Inc., Upper Saddle River, NJ, 2003.

Grossman, Michael, "On the Concept of Health Capital and the Demand for Health", Journal of Political Economy, March 1972, Vol. 80, No. 2, 223-255.

Harris B.L., Stergachis A. and Ried L.D., "The Effect of Drug Co-payments on Utilization and Cost of Pharmaceuticals in a Health Maintenance Organization”, Medical Care, October 1990, Vol. 28, No. 10, 907-917.

Heisler, M., Langa, K.M., Eby, E.L., Fendrick, A.M., Kabeto, M.U., and Piette, J.D., “The Health Effects of Restricting Prescription Medication Use Because of Cost", Medical Care, July 2004, Vol. 42, No.7, 626-634. 
Hellerstein, J.K., "The Importance of the Physician in the Generics versus Trade-Name Prescription Decision”, Rand Journal of Economics, Spring 1998, Vol. 29, No.1, 108-136.

Helms, J., Newhouse, J.P., and Phelps, C.E. , "Copayments and Demand for Medical Care: the California Medicaid Experience", Bell Journal of Economics, Spring 1978, Vol. 9, No. 1, 192208.

Honoré, B.E., "Trimmed LAD and Least Squares Estimation of Truncated and Censored Regression Models with Fixed Effects”, Econometrica, May 1992, Vol. 60, No. 3, 533-565.

Honoré, B.E. and Powell, J. L., "Pairwise Difference Estimators of Censored and Truncated Regression Models", Journal of Econometrics, September/October 1994, Vol. 64, No. 1-2, 241278.

Honoré, B.E., and Kyriazidou, E., "Estimation of Tobit-Type Models with Individual Specific Effects”, Econometric Reviews, 2000, Vol. 19, No. 3, 341-366

Huskamp, H.A., Deverka, P.A., Epstein, A.M., Epstein, R.S., McGuigan, K.A., and Frank, R.G., "The Effect of Incentive-based Formularies on Prescription Drug Use and Spending", New England Journal of Medicine, December 2003, Vol. 349, No. 23, 2224-2232 .

Johnson, R.E., Goodman, M.J., Hornbrook, M.C., and Eldredge, M.B., "The Impact of Increasing Patient Prescription Drug Cost Sharing on Therapeutic Classes of Drugs Received and on the Health Status of Elderly HMO Members", Health Services Research, April 1997, Vol. 32, No.1, 103-122.

Joyce, G.F., Escarce, J.J., Solomon, M.D. and Goldman, D.P., "Employer Drug Benefit Plans and Spending on Prescription Drugs", JAMA: The Journal of the American Medical Association, October 2002, Vol. 288, No. 14, 1733-1739.

Kaiser Family Foundation and Health Research and Educational Trust, Employer Health Benefits, 2006 Annual Survey, Kaiser Family Foundation, Menlo Park, CA, 2006.

http://www.kff.org/insurance/7527/index.cfm, 
Lichtenberg, F.R., "The Effect of Pharmaceutical Use and Innovation on Hospitalization and Mortality", Working Paper No. 5418, National Bureau of Economic Research, Cambridge, MA, January 1996.

Motheral B.R. and Fairman K.A., "Effect of a Three-tier Prescription Co-payment on Pharmaceutical and Other Medical Use", Medical Care, December 2001, Vol. 39, No. 12, 12931304.

Newhouse, J.P., Phelps, C.E. and Marquis, S.M., “On Having Your Cake and Eating It Too: Econometric Problems in Estimating the Demand for Health Services", Journal of Econometrics, August 1980, Vol. 13, No. 3, 365-390.

Pauly, M.V. and Zeng Y., "Adverse Selection and the Challenges to Stand-alone Prescription Drug Insurance”, Working Paper No. 9919, National Bureau of Economic Research, Cambridge, MA, August 2003.

Pilote L, Beck, C., Richard, H., and Eisenberg, M.J., "The Effects of Cost-sharing on Essential Drug Prescriptions, Use of Medical Care and Outcomes after Acute Myocardial Infarction in Elderly Patients”, Canadian Medical Association Journal, August 2002, Vol. 167, No. 3, 246252.

Pollak, R.A. and Wacher, M.L., "The Relevance of the Household Production Function and Its Implications for the Allocation of Time", Journal of Political Economy, April 1975, Vol. 83, No.2, 255-278.

Powell, J.L., "Least Absolute Deviations Estimation for the Censored Regression Model", Journal of Econometrics, July 1984, Vol. 25, No. 3, 303-325.

Powell, J.L., "Symmetrically Trimmed Least Squares Estimation for Tobit Models", Econometrica, November 1986, Vol. 54, No. 6, 1435-1460.

Rene C.J.A. van Vliet, "Predictability of Individual Health Care Expenditures", Journal of Risk and Insurance, September 1992, Vol. 59, No. 3, 443-461. 
Schneeweiss S., Walker, A.M., Glynn, R.J., Maclure, M., Dormuth, C., and Soumerai, S.B., “Outcomes of Reference Pricing for Angiotensin-Converting-Enzyme Inhibitors", New England Journal of Medicine, March 2002, Vol. 346, No. 11, 822-829.

Soumerai S.B., Ross-Degnan, A.D., and Gortmaker, S., "Payment Restrictions for Prescription Drugs under Medicaid: Effects on Therapy, Cost and Equity", New England Journal of Medicine, August 1987, Vol. 317, No. 9, 550-556.

Soumerai S.B., Ross-Degnan, A.D., Avorn, J., ,Mclaughlin, T., and Choodnovskiv, I., "Effects of Medicaid Drug-payment Limits on Admission to Hospitals and Nursing Homes”, New England Journal of Medicine, October 1991, Vol. 325, No. 15, 1072-1077.

Tamblyn, R., Laprise, R., Hanley, J.A., Abrahamowicz, M., Scott, S., Mayo, N., Hurley, J., Grad, R., Latimer, E., Perreault, R., McLeod, P., Huang, A., Larochelle, P., and Mallet, L., “Adverse Events Associated with Prescription Drug Cost-Sharing among Poor and Elderly Persons”, JAMA: The Journal of the American Medical Association, January 2001, Vol. 285, No.4, 421429.

Wooldridge, J.M., "Distribution-Free Estimation of Some Nonlinear Panel Data Models", Journal of Econometrics, May 1999, Vol. 90, No.1, 77-97.

Wooldridge, J.M., Econometric Analysis of Cross Section and Panel Data, MIT Press, 2002.

Yang, Zhou, Gilleskie, Donna B. and Norton, Edward C., "Prescription Drugs, Medical Care, and Health Outcomes: A Model of Elderly Health Dynamics", Working Paper No. 10964, National Bureau of Economic Research, Cambridge, MA, June 2006. 
Figure 1: Age Representation in Analysis Sample

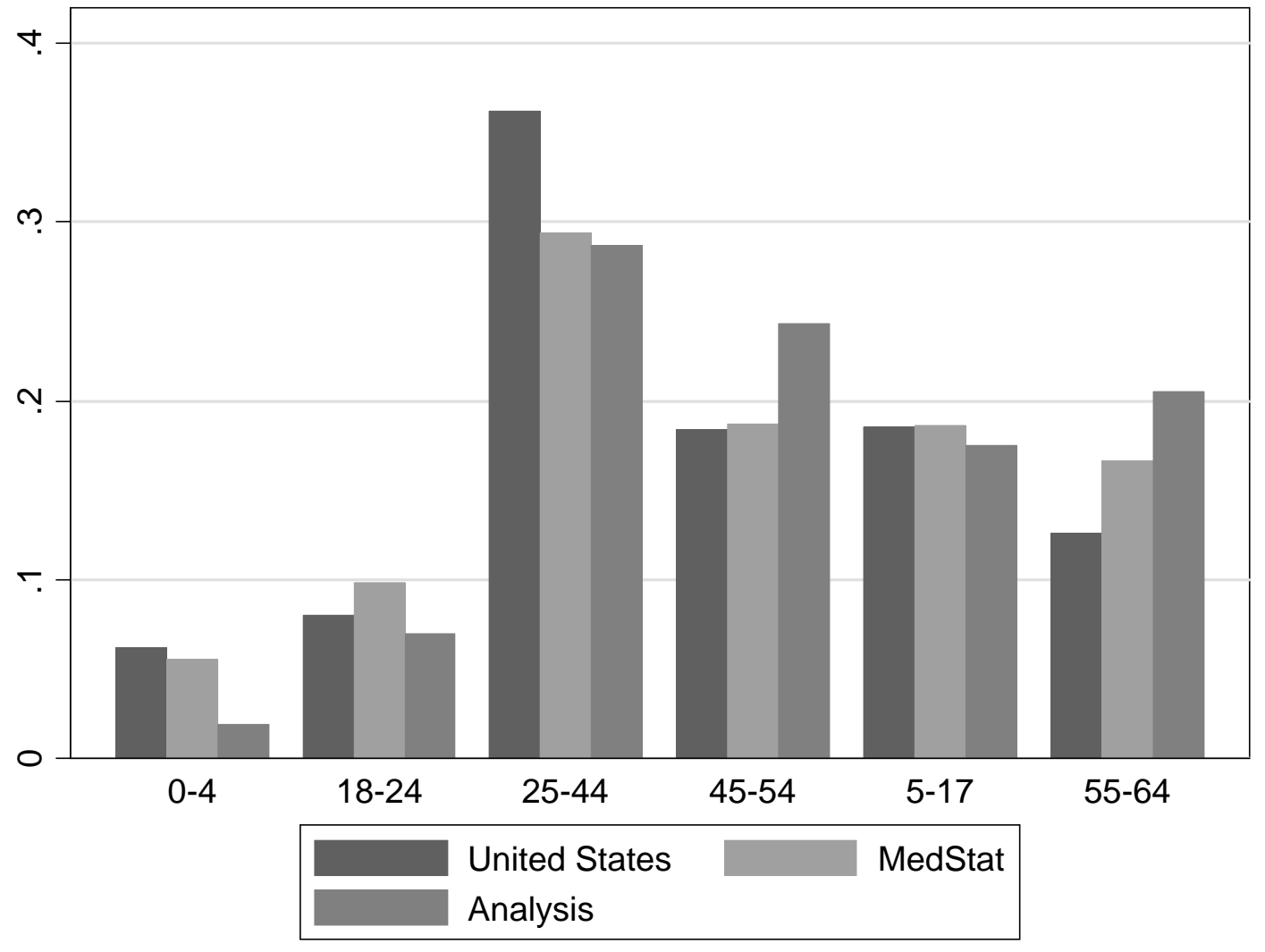


Figure 2: Region Representation in Analysis Sample

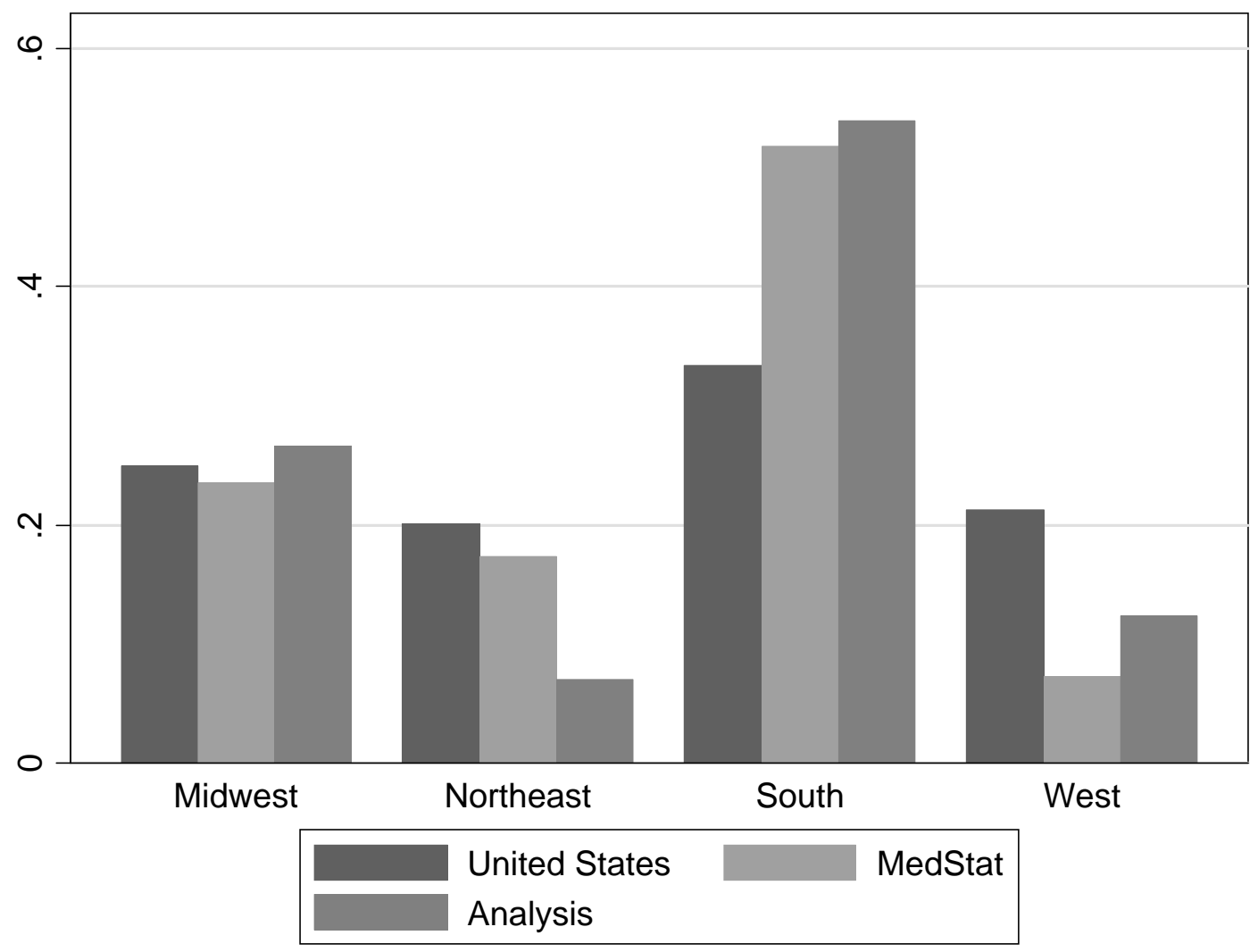


Figure 3: Drug Spending Representation in Analysis Sample

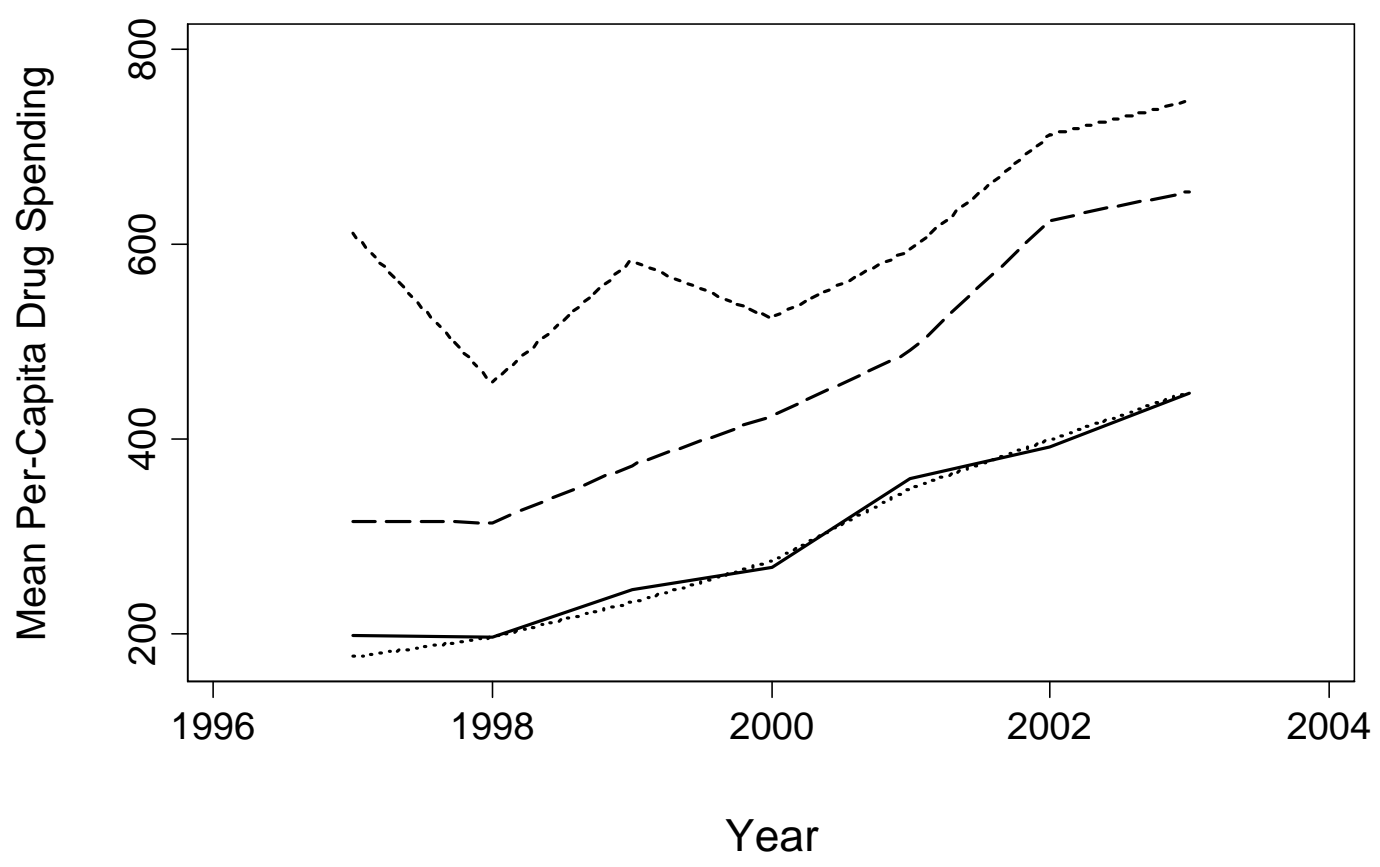

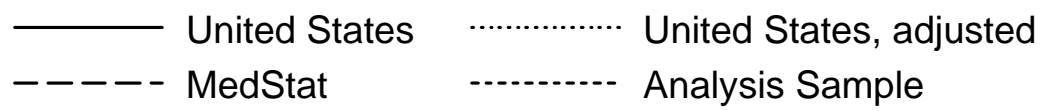


Figure 4: Medical Spending Representation in Analysis Sample
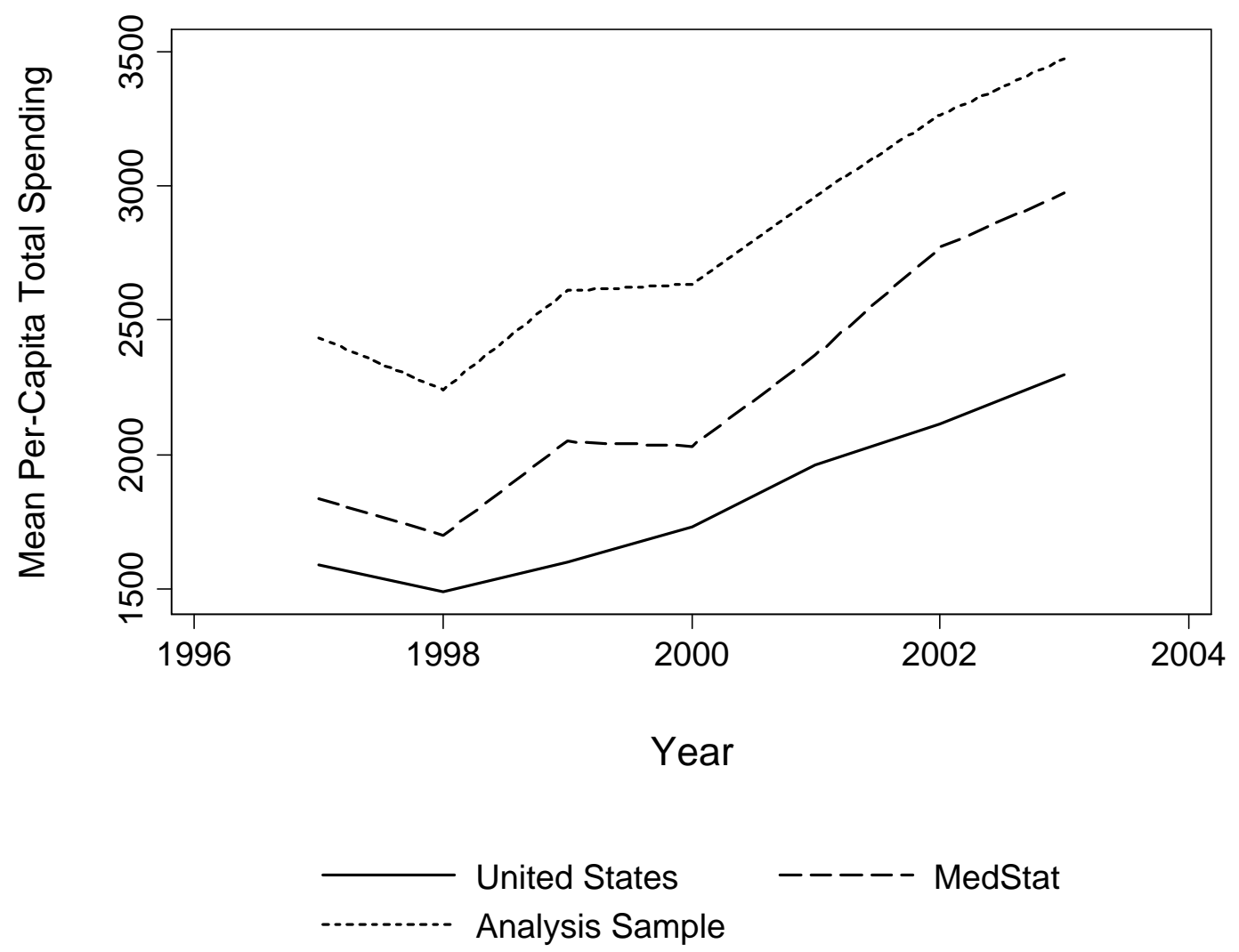
Figure 5: Inpatient Days in Analysis Sample and US

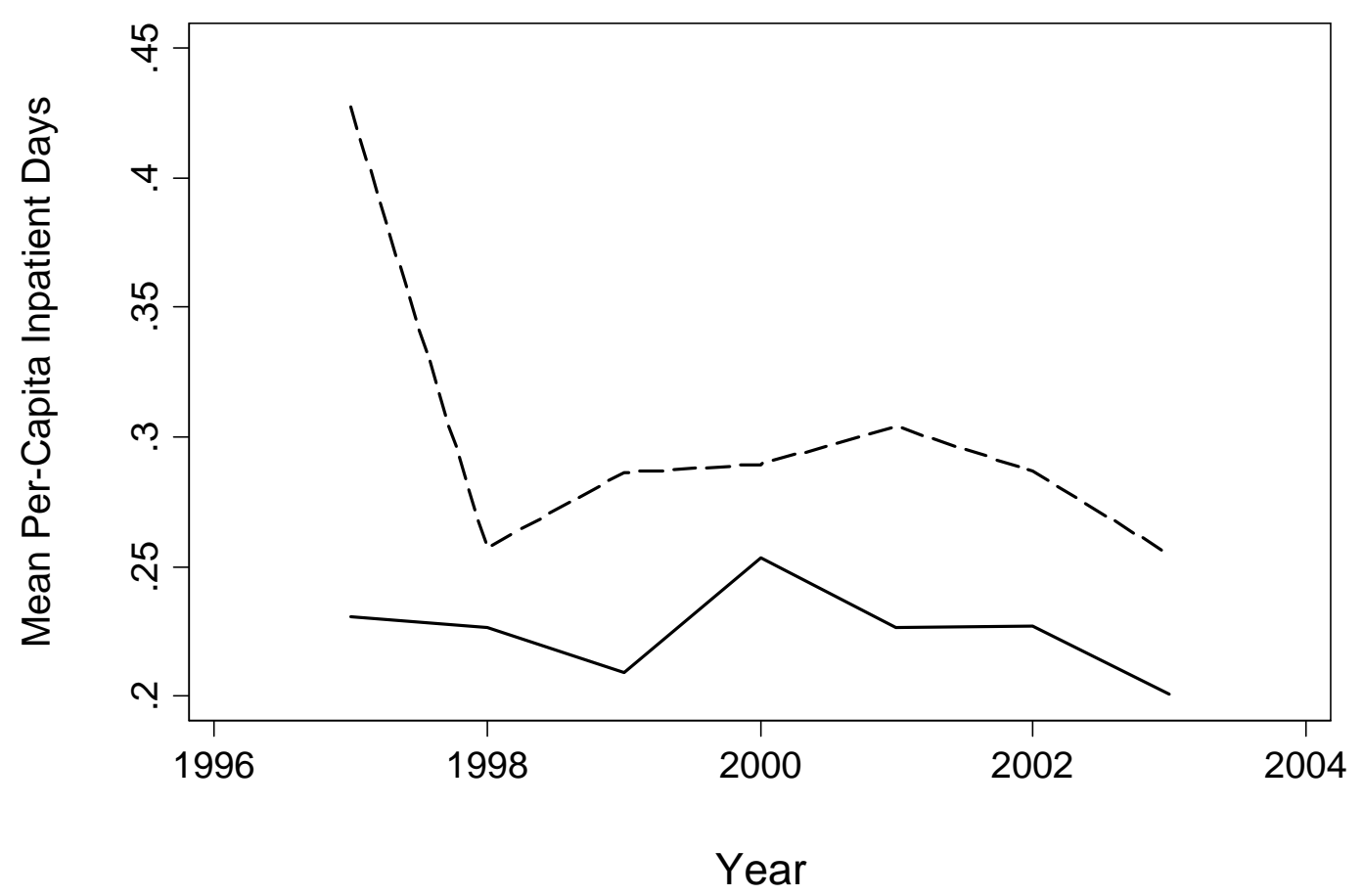

United States $\quad-----$ Analysis Sample 
Figure 6: Comparative Disease "Incidence”

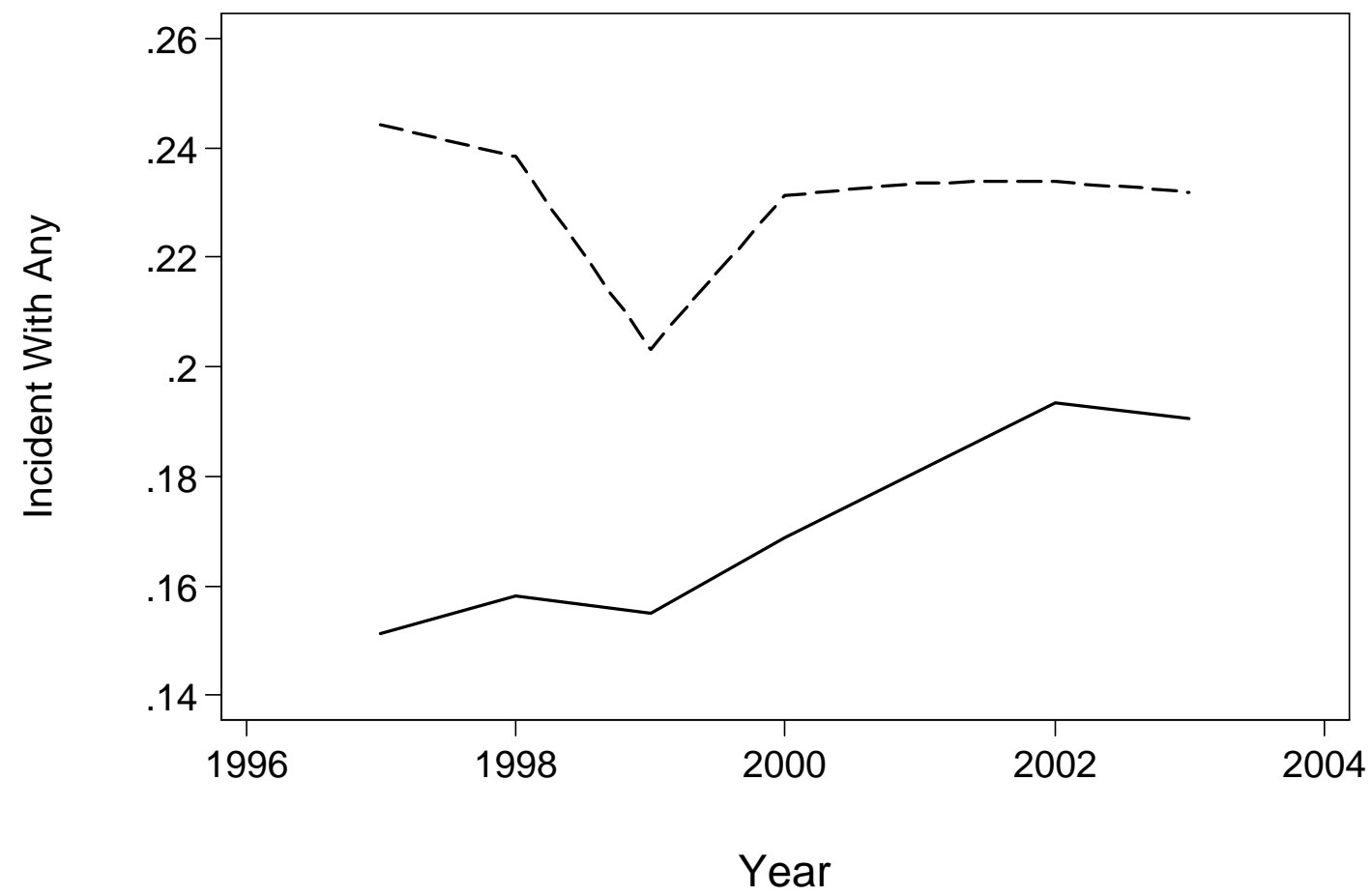

United States - - - - Analysis Sample 
Figure 7: Drug Co-Payment Representation in Analysis Sample

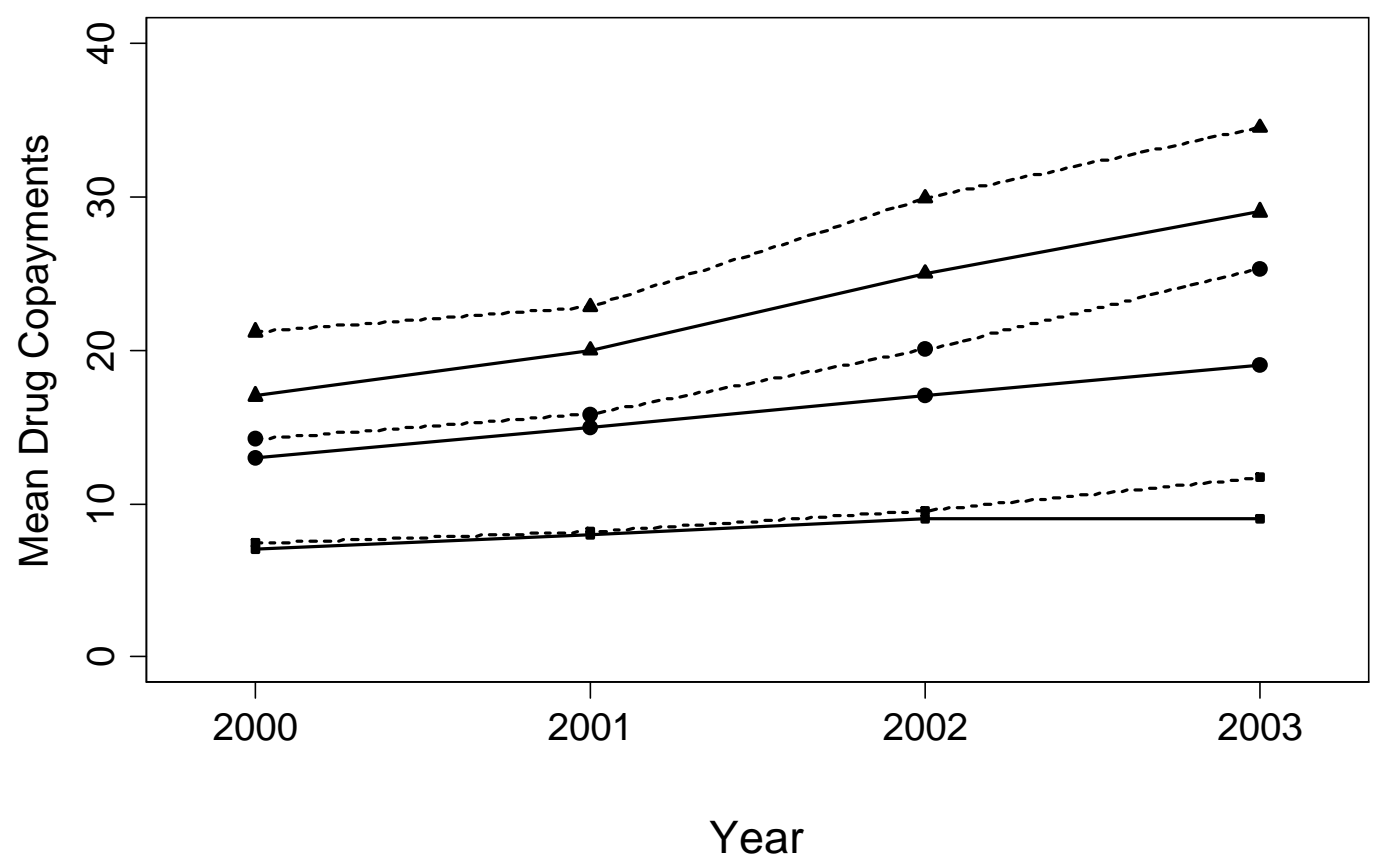

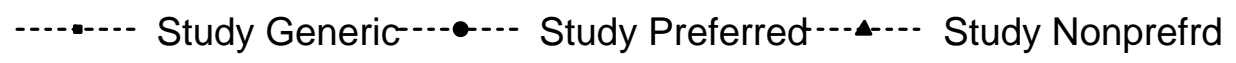
$\longrightarrow$ US Generic $\longrightarrow$ US Preferred $\longrightarrow$ US Nonpreferred 
Figure 8: Trends in Prescription Drug Spending and Prices

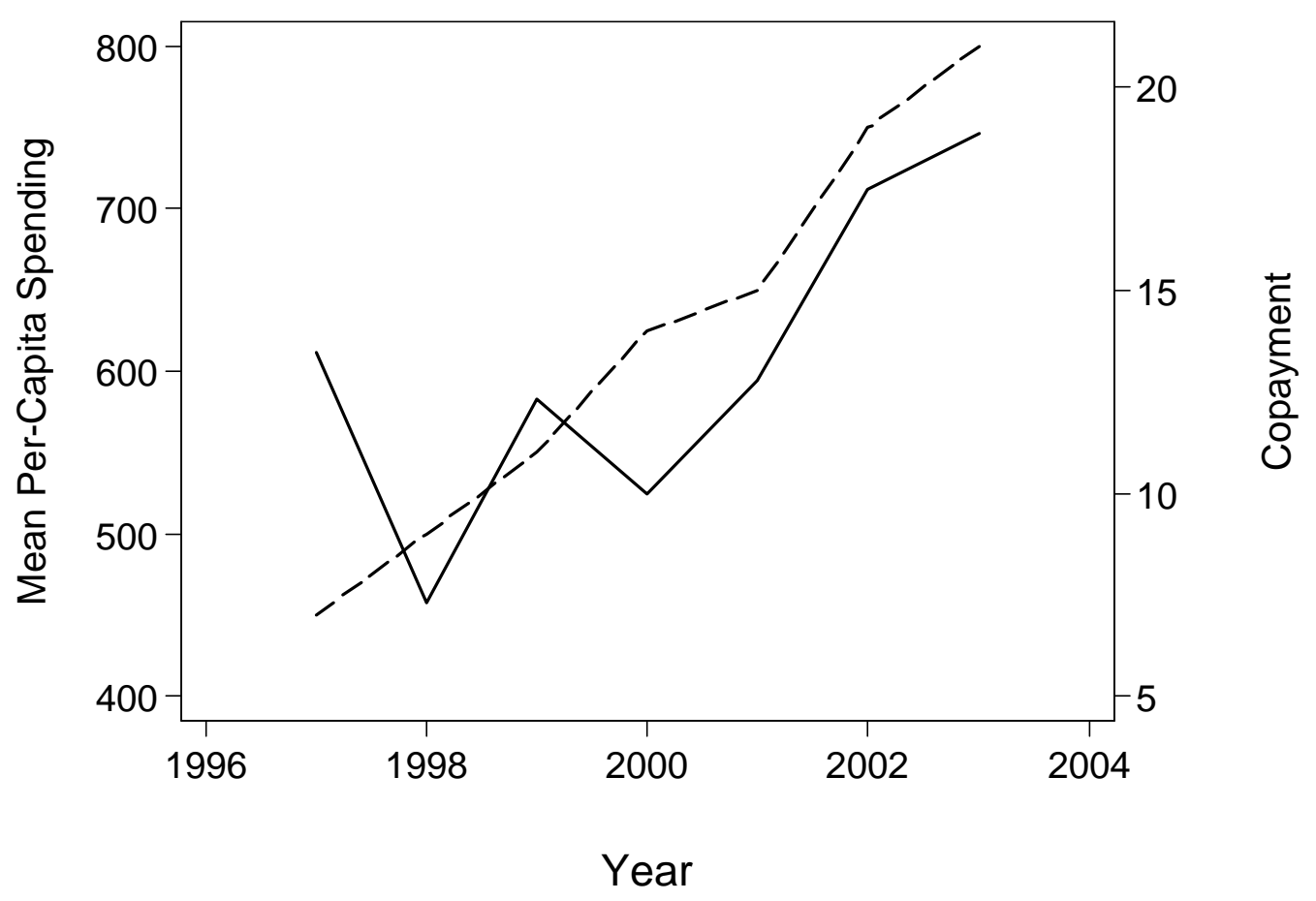

— Mean Drug Spending - - - Mean Copayment 
Table 1: Prescription Co-pay Index Market Basket Weights

\begin{tabular}{lccc}
\hline & Generic & Preferred Brand & $\begin{array}{c}\text { Non-Preferred } \\
\text { Brand }\end{array}$ \\
\hline CARD PLAN & 0.3580 & 0.3681 & 0.0908 \\
MAIL-ORDER & 0.0603 & 0.1025 & 0.0204 \\
\hline
\end{tabular}


Table 2: Prescription Drug Benefits for the Firms in Study Sample

\begin{tabular}{|c|c|c|c|c|c|c|c|c|}
\hline & & 1997 & 1998 & 1999 & 2000 & 2001 & 2002 & 2003 \\
\hline \multirow{3}{*}{1} & Card Plan & $\$ 4-\$ 4$ & $\$ 4-\$ 8$ & $\$ 4-\$ 8$ & & & & \\
\hline & Mail Plan & $\$ 4-\$ 4$ & $\$ 4-\$ 8$ & $\$ 4-\$ 8$ & & & & \\
\hline & Drug Price & 4.00 & 6.33 & 6.33 & & & & \\
\hline \multirow{3}{*}{2} & Card Plan & & & $\$ 12-\$ 12$ & $\$ 12-\$ 12$ & $\$ 12-\$ 12$ & $\$ 12-\$ 12$ & $\$ 12-\$ 16$ \\
\hline & Mail Plan & & & $\$ 12-\$ 12$ & $\$ 12-\$ 12$ & $\$ 20-\$ 20$ & $\$ 20-\$ 20$ & $\$ 20-\$ 36$ \\
\hline & Drug Price & & & 12.00 & 12.00 & 13.47 & 13.47 & 17.27 \\
\hline \multirow{3}{*}{3} & Card Plan & & $\$ 5-\$ 10$ & $\$ 5-\$ 15$ & $\$ 5-\$ 15-\$ 25$ & $\$ 5-\$ 15-\$ 25$ & $\$ 7-\$ 20-\$ 40$ & \\
\hline & Mail Plan & & $\$ 6-\$ 12$ & $\$ 6-\$ 18$ & $\$ 10-\$ 30-\$ 40$ & $\$ 10-\$ 30-\$ 40$ & $\$ 14-\$ 40-\$ 70$ & \\
\hline & Drug Price & & 8.22 & 11.25 & 14.08 & 14.08 & 19.87 & \\
\hline \multirow{3}{*}{4} & Card Plan & & & $\$ 5-\$ 10-\$ 25$ & $\$ 5-\$ 10-\$ 25$ & $\$ 5-\$ 15-\$ 30$ & $\$ 5-\$ 15-\$ 30$ & $\$ 5-\$ 15-\$ 30$ \\
\hline & Mail Plan & & & $\$ 10-\$ 20-\$ 45$ & $\$ 10-\$ 20-\$ 45$ & $\$ 10-\$ 30-\$ 70$ & $\$ 10-\$ 30-\$ 70$ & $\$ 10-\$ 30-\$ 85$ \\
\hline & Drug Price & & & 11.31 & 11.31 & 15.60 & 15.60 & 15.90 \\
\hline \multirow{3}{*}{5} & Card Plan & & & $\$ 4-\$ 12$ & $\$ 8-\$ 18$ & $\$ 10-\$ 20-\$ 30$ & $\$ 10-\$ 25-\$ 35$ & $\$ 11-\$ 27-\$ 42$ \\
\hline & Mail Plan & & & $\$ 12-\$ 36$ & $\$ 24-\$ 54$ & $\$ 20-\$ 40-\$ 60$ & $\$ 20-\$ 50-\$ 70$ & $\$ 22-\$ 54-\$ 84$ \\
\hline & Drug Price & & & 12.09 & 19. 21 & 20.20 & 23.72 & 26.27 \\
\hline \multirow{3}{*}{6} & Card Plan & $\$ 7-\$ 7$ & $\$ 9-\$ 9-\$ 15$ & $\$ 9-\$ 9-\$ 15$ & & & & \\
\hline & Mail Plan & $\$ 7-\$ 7$ & $\$ 9-\$ 9-\$ 15$ & $\$ 9-\$ 9-\$ 15$ & & & & \\
\hline & Drug Price & 7. 00 & 9.67 & 9.67 & & & & \\
\hline \multirow{3}{*}{7} & Card Plan & $\$ 5-\$ 10$ & $\$ 8-\$ 16$ & $\$ 8-\$ 16$ & $\$ 8-\$ 16-\$ 25$ & $\$ 8-\$ 16-\$ 25$ & $\$ 10-\$ 20-\$ 40$ & $\$ 10-\$ 20-\$ 40$ \\
\hline & Mail Plan & $\$ 5-\$ 10$ & $\$ 8-\$ 16$ & $\$ 8-\$ 16$ & $\$ 8-\$ 16-\$ 25$ & $\$ 8-\$ 16-\$ 25$ & $\$ 15-\$ 30-\$ 60$ & $\$ 15-\$ 30-\$ 60$ \\
\hline & Drug Price & 7.91 & 12.66 & 12.66 & 13. 66 & 13. 66 & 19.78 & 19.78 \\
\hline \multirow{3}{*}{8} & Card Plan & $\$ 5-\$ 10$ & $\$ 5-\$ 10$ & $\$ 5-\$ 10$ & $\$ 5-\$ 10$ & $\$ 6-\$ 15$ & $\$ 6-\$ 15$ & $\$ 6-\$ 15$ \\
\hline & Mail Plan & $\$ 8-\$ 15$ & $\$ 8-\$ 15$ & $\$ 8-\$ 15$ & $\$ 8-\$ 15$ & $\$ 9-\$ 25$ & $\$ 9-\$ 25$ & $\$ 9-\$ 25$ \\
\hline & Drug Price & 8.71 & 8.71 & 8.71 & 8.71 & 12.65 & 12.65 & 12.65 \\
\hline \multirow{3}{*}{9} & Card Plan & & & & & $\$ 10-\$ 10$ & $\$ 10-\$ 10$ & $\$ 10-\$ 20$ \\
\hline & Mai1 Plan & & & & & $\$ 15-\$ 20-\$ 30$ & $\$ 15-\$ 20-\$ 30$ & $\$ 20-\$ 45-\$ 60$ \\
\hline & Drug Price & & & & & 11.74 & 11.74 & 19.80 \\
\hline
\end{tabular}

Note: The first column indicates firm id. The $\$ \mathrm{X}-\$ \mathrm{Y}$ or $\$ \mathrm{X}-\mathrm{SY}-\mathrm{QZ}$ structures represent the 2-tier and 3-tier copayment schedules, respectively, where $\$ X$ denotes co-payment for generic drugs; $\$ Y$ denotes co-payment for brand drugs in a 2-tier schedule, and the co-payment for preferred brand drugs in a 3-tier schedule; $\$ Z$ denotes co-payment for non-preferred brand drugs in a 3-tier schedule. Drug prices are the calculated price index for each insurance plan based on the co-payments and population weights of each types of prescription 
Table 3: Descriptions of Variables

\begin{tabular}{ll}
\hline Variable & \multicolumn{1}{c}{ Description } \\
\hline RXS & Annual spending on prescription drugs \\
OUTS & Annual spending on outpatient services \\
INS & Annual spending on inpatient services \\
DAYSUPP & Prescription drugs demanded (in days) \\
NUMV & Number of outpatient visits \\
NUMADM & Number of inpatient admissions \\
RXP & Out of pocket prices for prescription drugs \\
DEDUCT & Deductible for medical services (for outpatient and inpatient) \\
COPAY & Co-payment for one physician office visit \\
AGEGROUP & Age group, 1=0-10, 2=11-18, 3=19-29, 4=30-39, 5=40-49, 6=50-59, 7=60-64 \\
AGE1YEAR- & The interaction of age group with Year \\
AGE7YEAR & $1=$ yes, $0=$ no \\
RETIRE & Dummy variables for year of data. Year97=1 if year=1997, etc. \\
YEAR97-YEAR03 &
\end{tabular}


Table 4: Summary Statistics

\begin{tabular}{|c|c|c|c|c|c|}
\hline $\begin{array}{l}\text { Variable } \\
\text { Name }\end{array}$ & Mean & Std & \% Zeroes & $\begin{array}{l}\text { \% Always } \\
\text { User }\end{array}$ & $\begin{array}{l}\% \text { Always } \\
\text { Non-User }\end{array}$ \\
\hline RXS & 624 & 1756 & $29.52 \%$ & $52.24 \%$ & $12.94 \%$ \\
\hline OUTS & 1614 & 5156 & $16.72 \%$ & $68.18 \%$ & $6.05 \%$ \\
\hline INS & 714 & 6918 & $95.78 \%$ & $0.42 \%$ & $87.35 \%$ \\
\hline TOTS & 2951 & 10242 & $13.00 \%$ & $74.83 \%$ & $4.45 \%$ \\
\hline DAYSUPP & 331 & 584 & $29.52 \%$ & $52.24 \%$ & $12.94 \%$ \\
\hline NUMV & 16.61 & 27.83 & $16.72 \%$ & $68.18 \%$ & $6.05 \%$ \\
\hline NUMADM & 0.06 & 0.33 & $95.78 \%$ & $0.42 \%$ & $87.35 \%$ \\
\hline RXP & 15.30 & 5.32 & - & - & - \\
\hline DEDUCT & 134 & 168 & - & - & - \\
\hline COPAY & 6.50 & 7.06 & - & - & - \\
\hline RETIRE & 0.18 & 0.39 & - & - & - \\
\hline AGE1TIME & 0.71 & 2.13 & - & - & - \\
\hline AGE2TIME & 0.83 & 2.31 & - & - & - \\
\hline AGE3TIME & 0.57 & 1.96 & - & - & - \\
\hline AGE4TIME & 0.98 & 2.48 & - & - & - \\
\hline AGE5TIME & 1.47 & 2.93 & - & - & - \\
\hline AGE6TIME & 1.58 & 2.98 & - & - & - \\
\hline YEAR98 & 0.05 & 0.22 & - & - & - \\
\hline YEAR99 & 0.11 & 0.32 & - & - & - \\
\hline YEAR00 & 0.19 & 0.39 & - & - & - \\
\hline YEAR01 & 0.22 & 0.41 & - & - & - \\
\hline YEAR02 & 0.22 & 0.41 & - & - & - \\
\hline YEAR03 & 0.17 & 0.38 & - & - & - \\
\hline $\mathbf{N}$ & & & 1713879 & & \\
\hline \# of Individual & & & 526086 & & \\
\hline
\end{tabular}


Table 5: Percentage of People Switching Among Insurance Plans

\begin{tabular}{|c|c|c|c|c|c|c|c|c|}
\hline & & 97 & 98 & 99 & 00 & 01 & 02 & 03 \\
\hline \multirow[t]{2}{*}{ Firm 1} & Medical & - & 0 & 0 & & & & \\
\hline & Drug & - & 0 & 0 & & & & \\
\hline \multirow[t]{2}{*}{ Firm 2} & Medical & & & - & 0 & 0.11 & 1.8 & 2.18 \\
\hline & Drug & & & - & 0 & 0 & 0 & 0 \\
\hline \multirow[t]{2}{*}{ Firm 3} & Medical & & - & 0 & 2.88 & 1.11 & 1.14 & \\
\hline & Drug & & - & 0 & 0 & 0 & 0 & \\
\hline \multirow[t]{2}{*}{ Firm 4} & Medical & & & - & 0.13 & 0.19 & 0.29 & 0.97 \\
\hline & Drug & & & - & 0 & 0 & 0 & 0 \\
\hline \multirow[t]{2}{*}{ Firm 5} & Medical & & & - & 0 & 7.13 & 0 & 0 \\
\hline & Drug & & & - & 0 & 0 & 0 & 0 \\
\hline \multirow[t]{2}{*}{ Firm 6} & Medical & - & 0 & 0 & & & & \\
\hline & Drug & - & 0 & 0 & & & & \\
\hline \multirow[t]{2}{*}{ Firm 7} & Medical & - & 1.13 & 0.99 & 0.92 & 1.17 & 0.39 & 0 \\
\hline & Drug & - & 0 & 0 & 0 & 0 & 0 & 0 \\
\hline \multirow[t]{2}{*}{ Firm 8} & Medical & - & 0.45 & 0.34 & 0.14 & 0.58 & 0 & 0 \\
\hline & Drug & - & 0 & 0 & 0 & 0 & 0 & 0 \\
\hline \multirow[t]{2}{*}{ Firm 9} & Medical & & & & & - & 0 & 0 \\
\hline & Drug & & & & & - & 0 & 0 \\
\hline
\end{tabular}

Note: The number in each cell represents the percentage of people within a firm who switch their medical insurance benefits or prescription drug insurance benefits from previous year to the indicated year. 
Table 6: Changes in Plan Benefit Design

Medical plan change

\begin{tabular}{|c|c|c|c|}
\hline & No & Yes & Total \\
\hline No & 11 & 5 & 16 \\
\hline Yes & 11 & 7 & 18 \\
\hline Total & 22 & 12 & 34 \\
\hline
\end{tabular}

Pearson's $\chi^{2}=0.22, \mathrm{p}=0.6$ 
Table 7: Estimation Results for Spending Equations

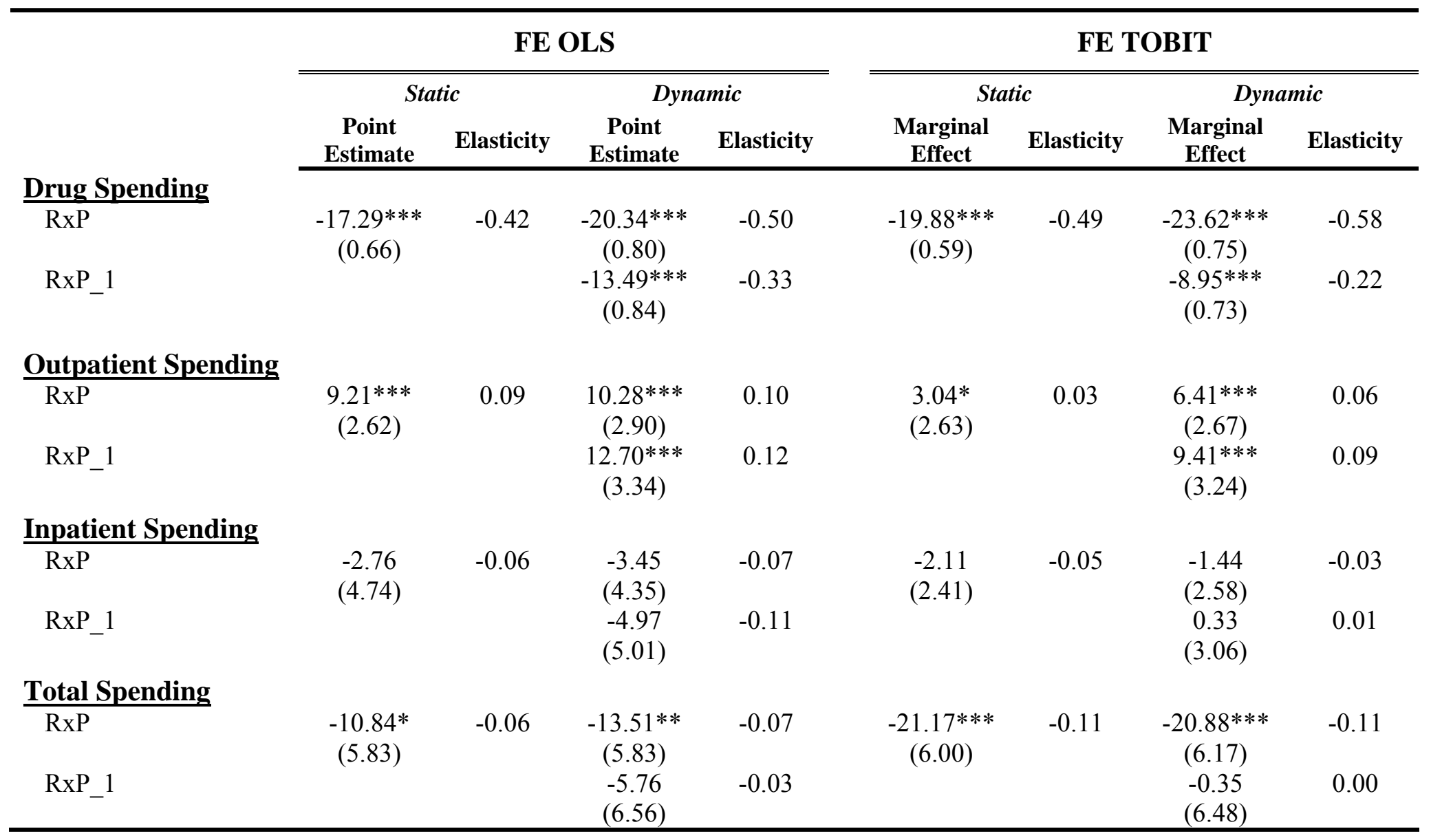

Note: Standard errors are derived via an individual-level block bootstrap with 250 replications.

*** Statistically significant at 0.001 level $* *$ Statistically significant at 0.05 level * Statistically significant at 0.1 level. 
Table 8: Estimation Results for Quantity Equations

\begin{tabular}{|c|c|c|c|c|c|c|c|c|}
\hline \multirow[b]{4}{*}{ Drug Supply Days } & \multicolumn{4}{|c|}{ FE OLS } & \multicolumn{4}{|c|}{ FE Poisson } \\
\hline & \multicolumn{2}{|c|}{ Static } & \multicolumn{2}{|c|}{ Dynamic } & \multicolumn{2}{|c|}{ Static } & \multicolumn{2}{|c|}{ Dynamic } \\
\hline & $\begin{array}{c}\text { Point } \\
\text { Estimate }\end{array}$ & Elasticity & $\begin{array}{c}\text { Point } \\
\text { Estimate }\end{array}$ & Elasticity & $\begin{array}{c}\text { Marginal } \\
\text { Effect }\end{array}$ & Elasticity & $\begin{array}{c}\text { Marginal } \\
\text { Effect }\end{array}$ & Elasticity \\
\hline & & & & & & & & \\
\hline $\mathrm{RxP}$ & $\begin{array}{c}-9.66 * * * \\
(0.16)\end{array}$ & -0.45 & $\begin{array}{c}-11.47^{* * *} \\
(0.18)\end{array}$ & -0.53 & $\begin{array}{c}-12.94 * * * \\
(0.24)\end{array}$ & -0.60 & $\begin{array}{c}-15.7 * * * \\
(0.21)\end{array}$ & -0.73 \\
\hline $\mathrm{RxP}_{-} 1$ & & & $\begin{array}{c}-8.60 * * * \\
0.18\end{array}$ & -0.40 & & & $\begin{array}{c}-10.6^{* * *} \\
(0.21)\end{array}$ & -0.49 \\
\hline \multicolumn{9}{|l|}{ Outpatient Visits } \\
\hline$\overline{\mathrm{RxP}}$ & $\begin{array}{c}0.05^{* * *} \\
(0.02)\end{array}$ & 0.05 & $\begin{array}{c}0.05^{* * *} \\
(0.01)\end{array}$ & 0.05 & $\begin{array}{l}-0.013 \\
(0.02)\end{array}$ & -0.01 & $\begin{array}{c}-0.026^{* *} \\
(0.01)\end{array}$ & -0.02 \\
\hline $\mathrm{RxP}_{-} 1$ & & & $\begin{array}{c}0.18^{* * *} \\
(0.01)\end{array}$ & 0.17 & & & $\begin{array}{c}0.101 * * * \\
(0.02)\end{array}$ & 0.09 \\
\hline \multicolumn{9}{|l|}{ Hospital Admission } \\
\hline $\mathrm{RxP}$ & $\begin{array}{l}-0.0003^{*} \\
(0.0002)\end{array}$ & -0.07 & $\begin{array}{l}-0.0003 \\
(0.0002)\end{array}$ & -0.08 & $\begin{array}{l}-0.002 \\
(0.002)\end{array}$ & $-0.003 \dagger$ & $\begin{array}{l}-0.0026 \\
(0.0015)\end{array}$ & $-0.03 \dagger$ \\
\hline $\mathrm{RxP}_{-} 1$ & & & $\begin{array}{c}-0.0005^{* *} \\
(0.0002)\end{array}$ & -0.13 & & & $\begin{array}{c}-0.0043 * * \\
(0.0016)\end{array}$ & $-0.05 \dagger$ \\
\hline
\end{tabular}

Note: Standard errors are derived via an individual-level block bootstrap with 250 replications.

*** Statistically significant at 0.001 level $* *$ Statistically significant at 0.05 level * Statistically significant at 0.1 level.

$\dagger$ These elasticities are calculated using the number of inpatient admissions for inpatient care users. The average inpatient admission for users is 1.29 admissions per year, and for the whole population is 0.06 per year. 
Table 9: Summary Statistics, Stratified by Health

\begin{tabular}{|c|c|c|c|c|}
\hline & \multicolumn{2}{|c|}{$\begin{array}{c}\begin{array}{c}\text { Without Chronic } \\
\text { Condition }\end{array} \\
\end{array}$} & \multicolumn{2}{|c|}{$\begin{array}{c}\text { With Chronic } \\
\text { Condition }\end{array}$} \\
\hline & Mean & Std Dev & Mean & Std Dev \\
\hline age & 33.73 & 18.12 & 48.16 & 15.14 \\
\hline sex & 0.48 & 0.50 & 0.50 & 0.50 \\
\hline retire & 0.15 & 0.35 & 0.34 & 0.47 \\
\hline $\mathrm{rxp} \mathrm{cm}$ & 13.86 & 3.76 & 13.50 & 3.84 \\
\hline rxp_cm 1 & 12.06 & 3.19 & 11.73 & 3.26 \\
\hline ided & 54.86 & 76.44 & 68.37 & 77.11 \\
\hline ided_1 & 54.81 & 74.14 & 68.66 & 75.31 \\
\hline copay & 8.35 & 6.92 & 7.17 & 6.84 \\
\hline copay_1 & 7.05 & 5.66 & 5.98 & 5.58 \\
\hline rxs & 385 & -1514 & 1291 & 2445 \\
\hline outs & 1246 & 4026 & 2936 & 7732 \\
\hline ins & 370 & 4606 & 1614 & 11284 \\
\hline tots & 2000 & 7268 & 5841 & 16115 \\
\hline days & 180 & 374 & 745 & 846 \\
\hline outq & 13 & 23 & 29 & 39 \\
\hline numadm & 0.04 & 0.24 & 0.12 & 0.49 \\
\hline indays & 0.15 & 1.87 & 0.60 & 4.68 \\
\hline Number Obs & \multicolumn{2}{|c|}{1280086} & \multicolumn{2}{|c|}{465426} \\
\hline
\end{tabular}


Table 10: Linear Fix Effect Regression Results for Spending, Stratified by Health

\begin{tabular}{|c|c|c|c|c|c|c|c|c|}
\hline \multirow[b]{4}{*}{ Drug Spendir } & \multicolumn{4}{|c|}{ Without Chronic Condition } & \multicolumn{4}{|c|}{ With Chronic Condition } \\
\hline & \multicolumn{2}{|c|}{ Linear FE } & \multicolumn{2}{|c|}{ Tobit FE } & \multicolumn{2}{|c|}{ Linear FE } & \multicolumn{2}{|c|}{ Tobit FE } \\
\hline & $\begin{array}{c}\text { Point } \\
\text { Estimate }\end{array}$ & Std Dev & $\begin{array}{c}\text { Marginal } \\
\text { Effect } \\
\end{array}$ & Std Dev & $\begin{array}{c}\text { Point } \\
\text { Estimate }\end{array}$ & Std Dev & $\begin{array}{c}\text { Marginal } \\
\text { Effect } \\
\end{array}$ & Std Dev \\
\hline & & & & & & & & \\
\hline $\mathrm{RxP}$ & -8.14 & 0.65 & -12.16 & 0.56 & -49.31 & 1.69 & -42.21 & 1.21 \\
\hline Lag RxP & -5.08 & 0.71 & -4.94 & 0.68 & -27.26 & 1.76 & -14.10 & 1.46 \\
\hline \multicolumn{9}{|c|}{ Outpatient Spending } \\
\hline & 8.57 & 2.18 & 2.56 & 2.35 & 13.20 & 7.54 & 16.39 & 6.22 \\
\hline & 13.78 & 2.38 & 9.85 & 2.84 & 10.47 & 7.87 & 10.69 & 7.42 \\
\hline \multicolumn{9}{|c|}{ Inpatient Spending } \\
\hline $\mathrm{RxP}$ & -1.09 & 2.34 & -1.44 & 1.96 & -11.39 & 13.61 & -1.18 & 3.02 \\
\hline Lag RxP & 0.23 & 2.56 & 1.66 & 2.43 & -19.87 & 14.20 & -1.77 & 3.76 \\
\hline \multicolumn{9}{|c|}{ Total Spending } \\
\hline & -0.66 & 3.62 & -12.34 & 4.61 & -47.50 & 17.02 & -38.08 & 15.38 \\
\hline & 8.92 & 3.95 & 7.45 & 5.60 & -36.67 & 17.76 & -15.13 & 18.38 \\
\hline Number Obs & \multicolumn{4}{|c|}{1280086} & \multicolumn{4}{|c|}{465426} \\
\hline
\end{tabular}

Note: Standard errors are derived via an individual-level block bootstrap with 50 replications. 